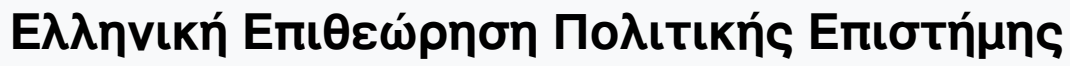

Tó 38 (2011)

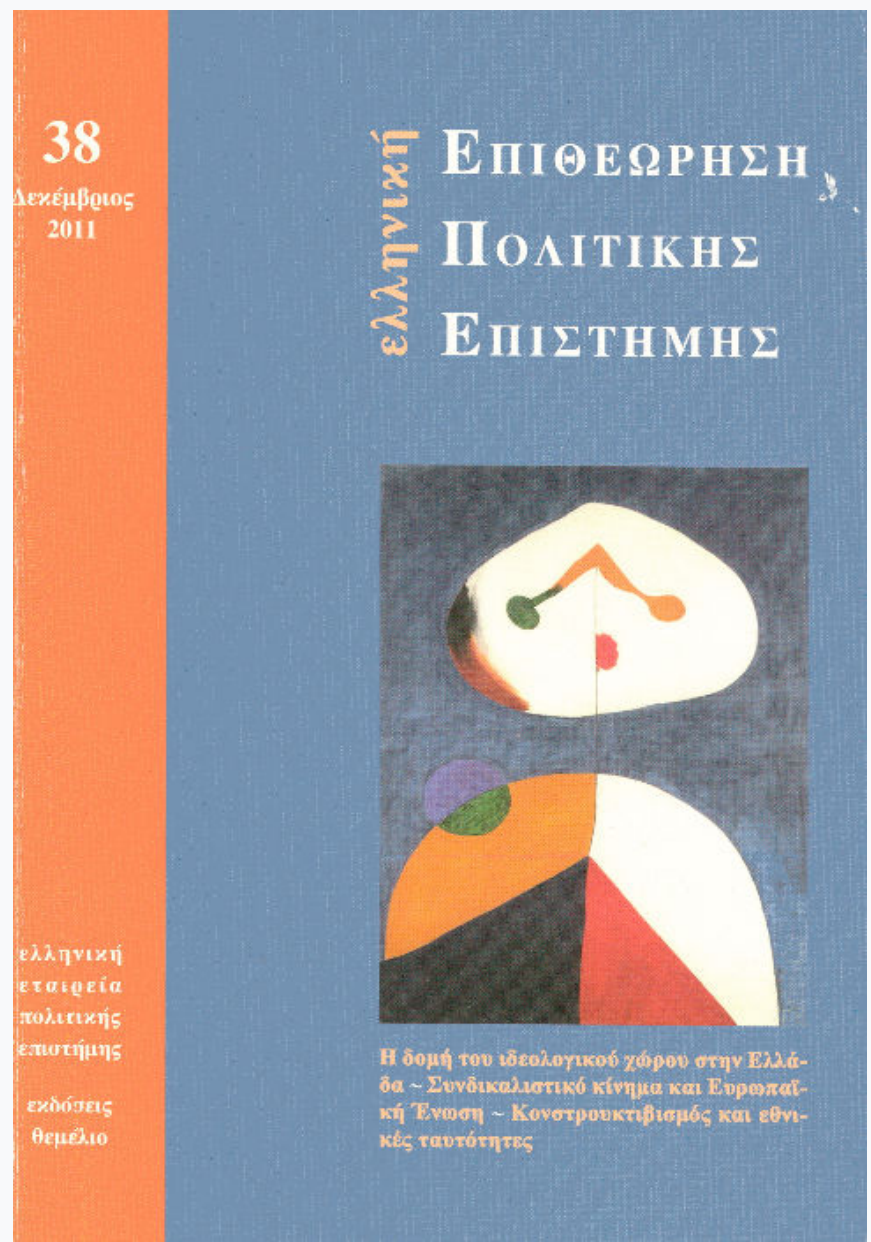

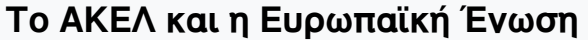

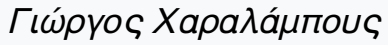

doi: $\underline{10.12681 / h p s a .14526}$

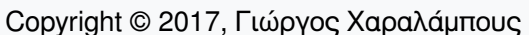

\section{(2) $(\odot \otimes \odot$}

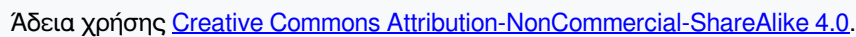

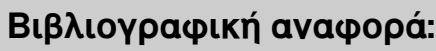

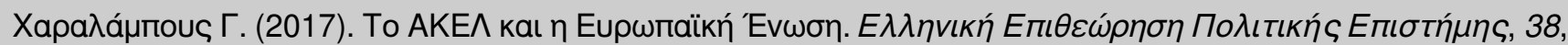
51-87. https://doi.org/10.12681/hpsa.14526 


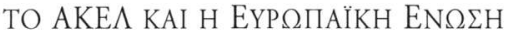

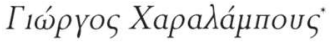

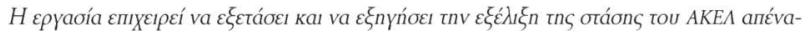

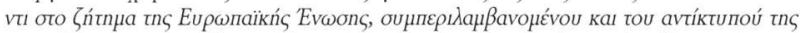

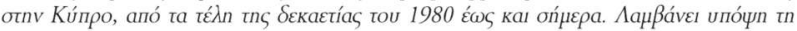

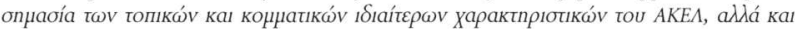

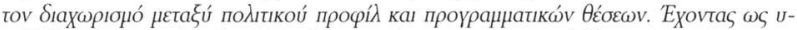

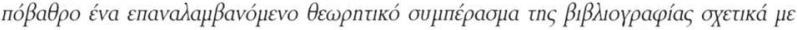

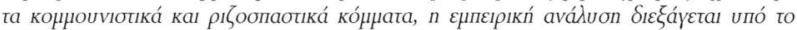

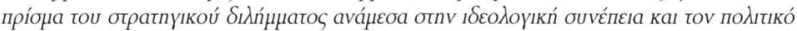

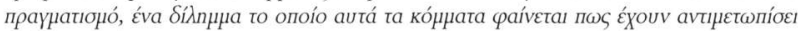
aпó tnv apXń tnş пореías tous.

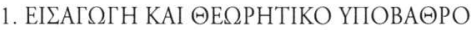

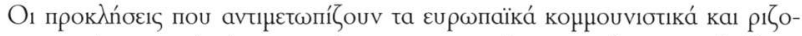

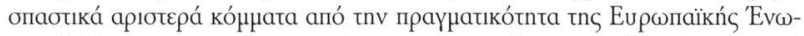

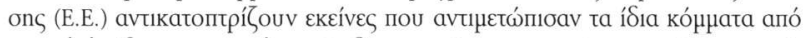

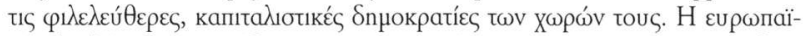

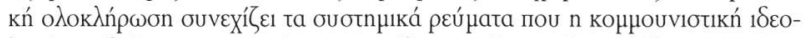

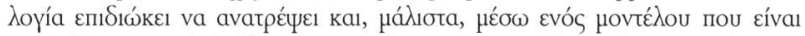

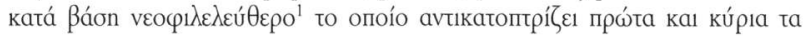

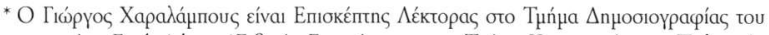

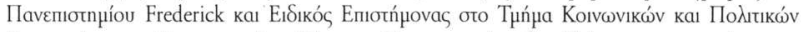

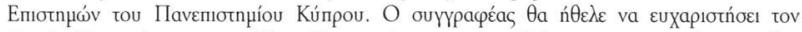

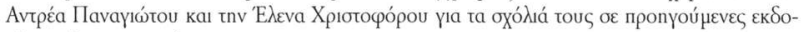
Xéç autrís tnç epyaớas.

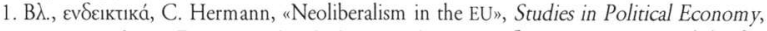

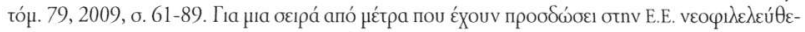

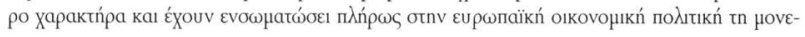




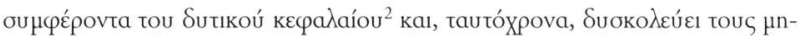

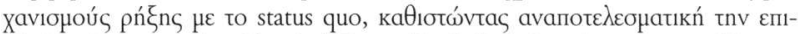

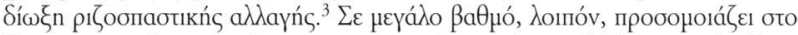

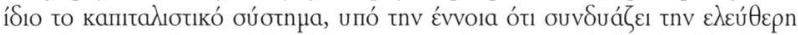

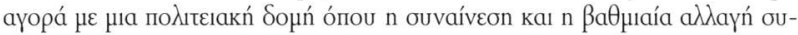

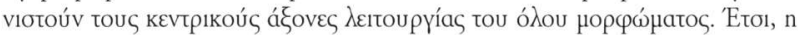

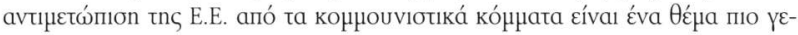

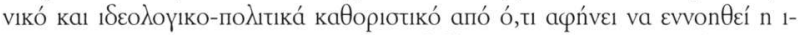

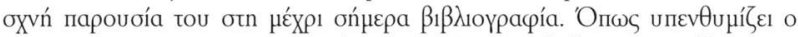

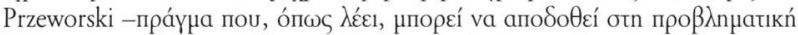

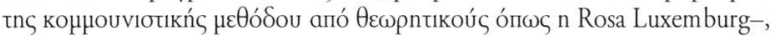

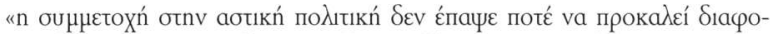

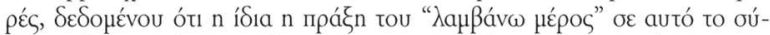

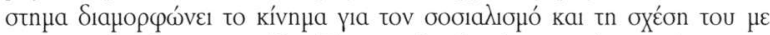

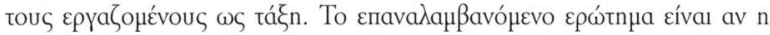

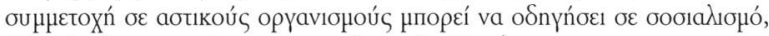

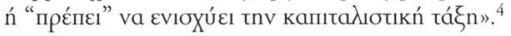

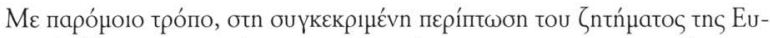

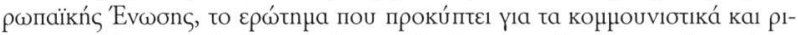

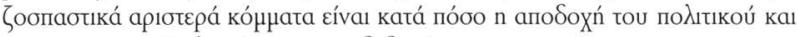

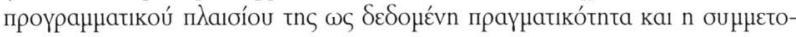

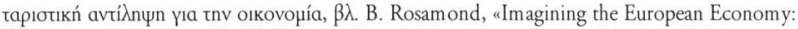
Competitiveness and the Social Construction of Europe as an Economic Spacen, New Political

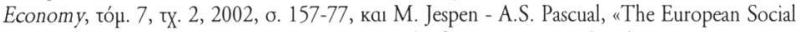
Model: An Exercise in Decostruction", Journal of European Social Policy, tóp. 15, тx. 3, 2005, o. 231-245.

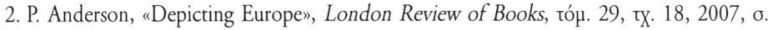
13-21.

3. P. Mair, "Political Opposition and the European Union», Government and Opposition, тóp. 42, тx. 1, 2007, б. 1-17.

4. A. Przeworski, "Social Democracy as a Historical Phenomenon", New Left Review,

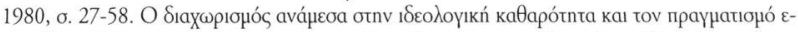

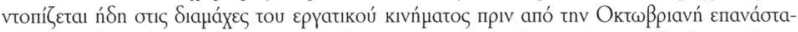

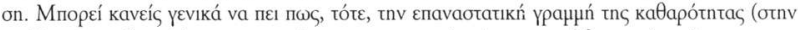

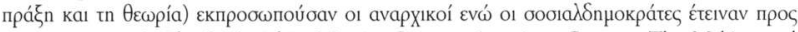

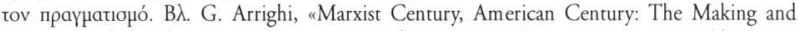
Remaking of the Labour Movement", New Left Review, tóp. I, тX. 79, 1990, ๔. 29-64. 


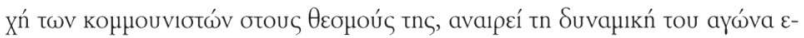

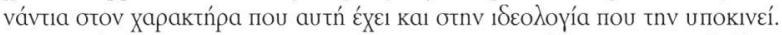

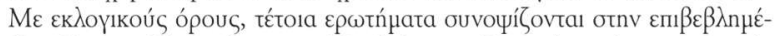

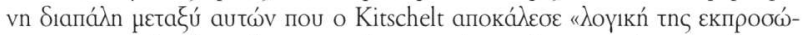

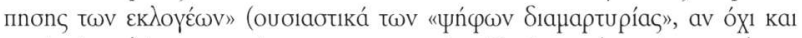

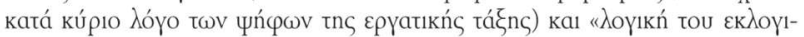

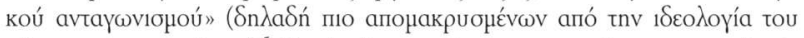

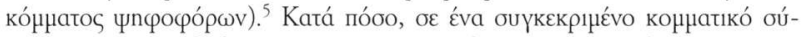

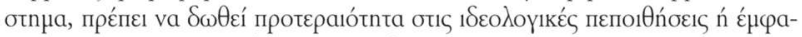

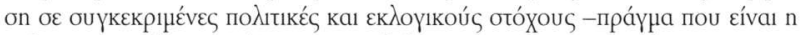

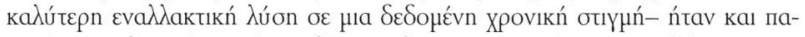

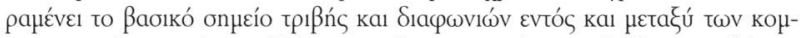

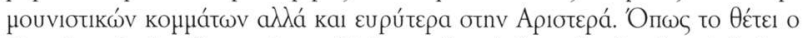

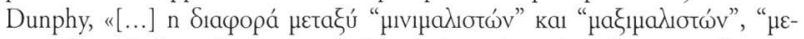

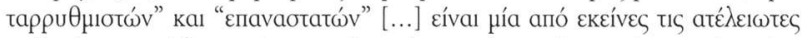

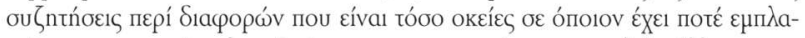

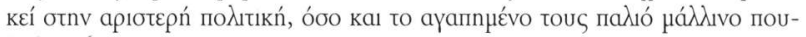

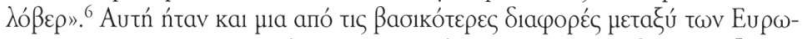

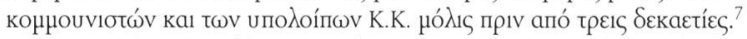

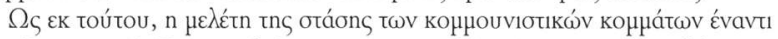

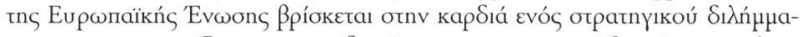

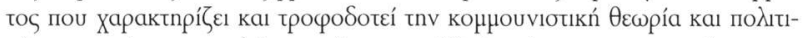

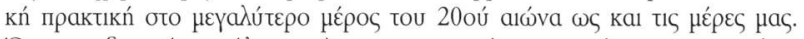

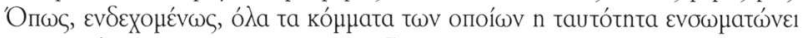

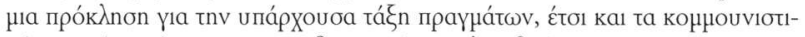

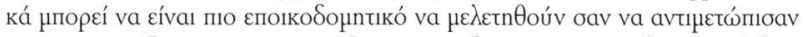

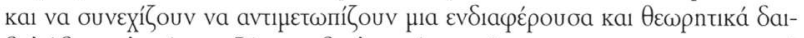

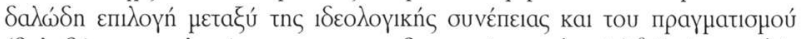

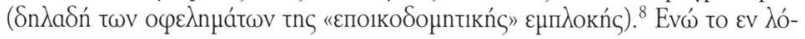

5. H. Kitschelt, The Logics of Party Formation: Ecological Politics in Belgium and West Germany, Cornell University Press, Ithaca 1989.

6. R. Dunphy, Contesting Capitalism: Left Parties and European Integration, Manchester University Press, Manchester 2004, o. 13.

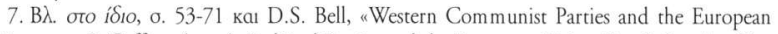

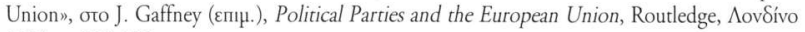
1996, o. 220-235.

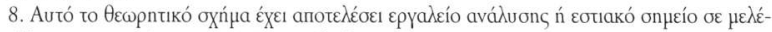

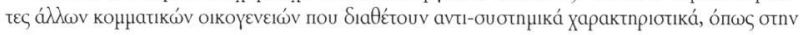




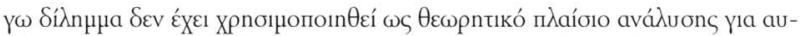

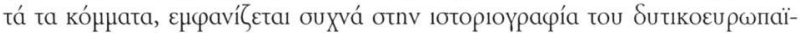

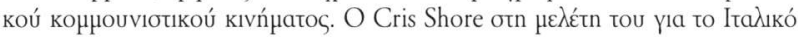

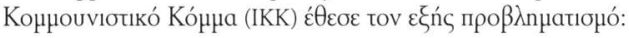

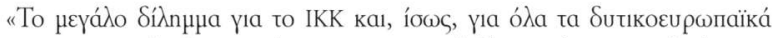

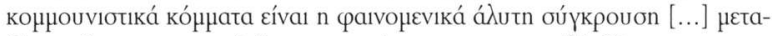

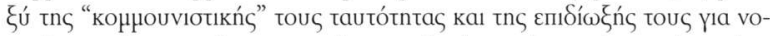

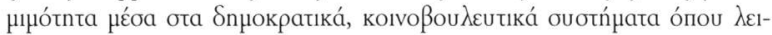

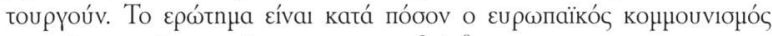

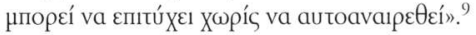

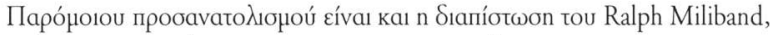

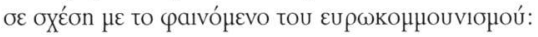

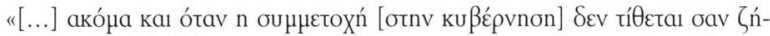

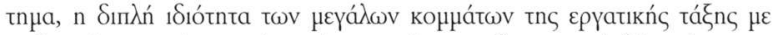

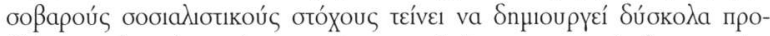

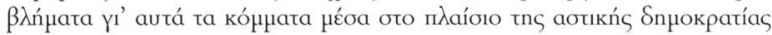

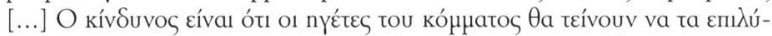

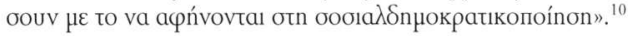

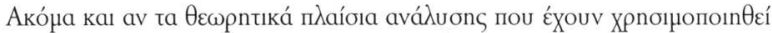
үıа tnv ع

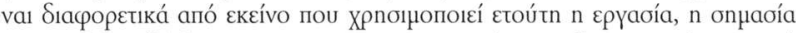

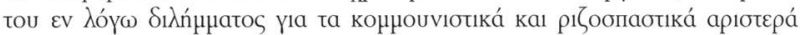

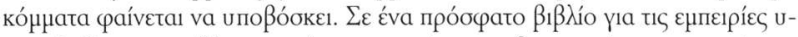

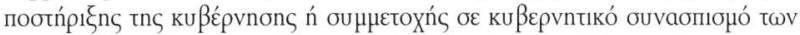

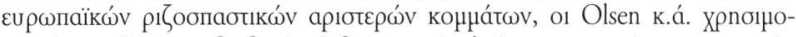

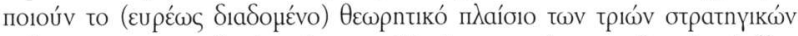

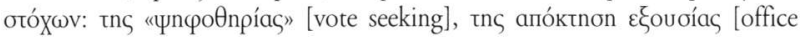

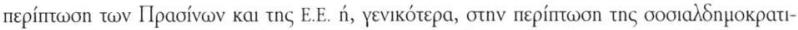

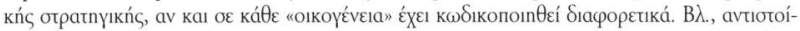

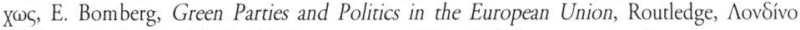
1998, ka A. Przeworski, «Social Democracy as a Historical Phenomenon», ó.r.

9. C. Shore, Italian comm unism: the escape from Leninism: an anthropological perspective,

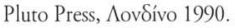

10. R. Miliband, "Constitutionalism and Revolution: Notes on Eurocommunism", The Socialist Register, tón. I, тx. xvi, 1978, б. 168-169. 


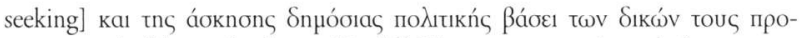

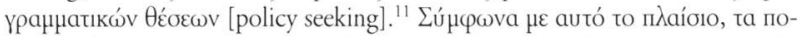

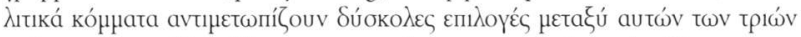

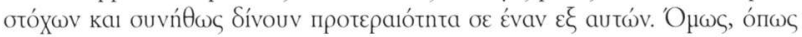

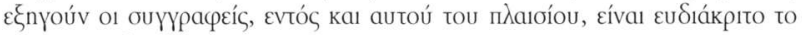

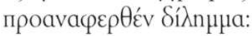

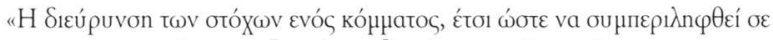

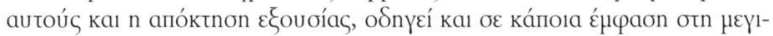

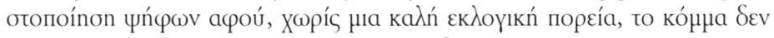

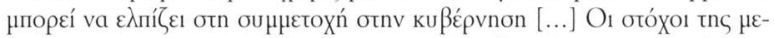

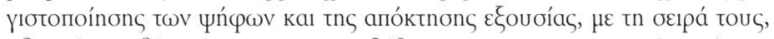

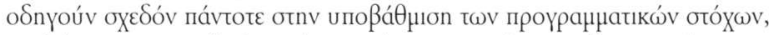

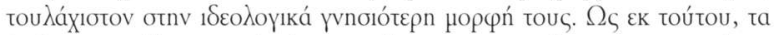

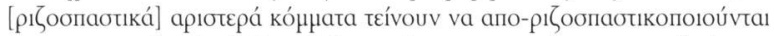

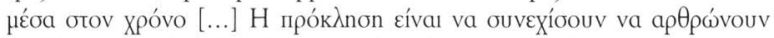

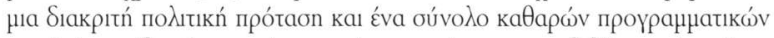

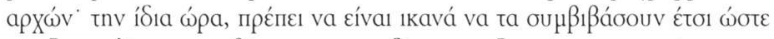

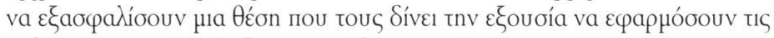

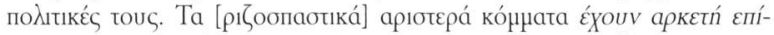

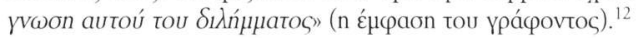

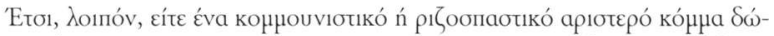

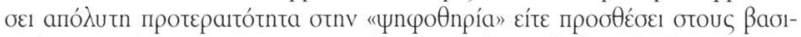

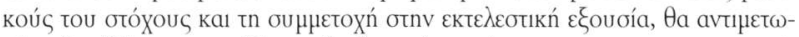

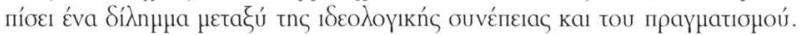

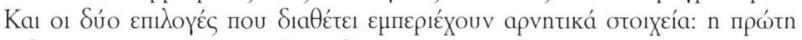

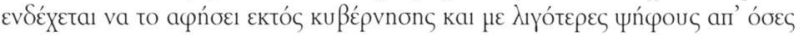

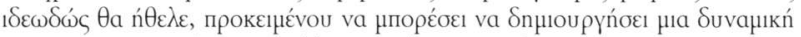

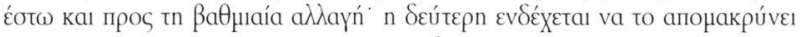

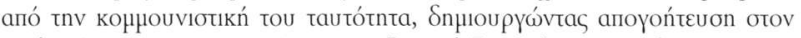

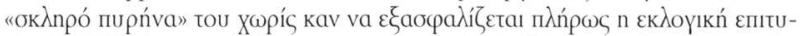

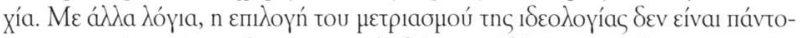

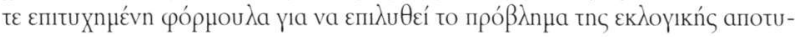

11. J. Olsen - M. Koss - D. Hough, Left Parties in National Governments, Palgrave, Baginstoke 2010. Bג., enionc, W.C. Muller - K. Strom. Policy, office, or votes: How political parties in Western Europe make hard decisions, Cambridge University Press, Cambridge 1999.

12. J. Olsen - M. Koss - D. Hough, Left Parties in National Governments, ó.п., б. 11-12. 


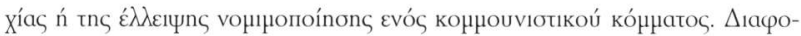

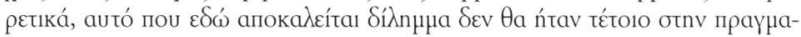

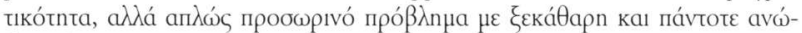
Suvn $\lambda u ́ o n$.

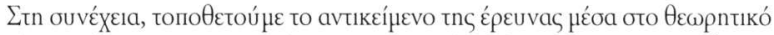

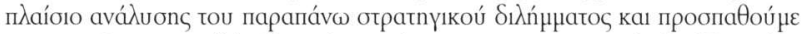

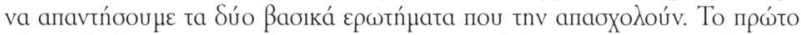

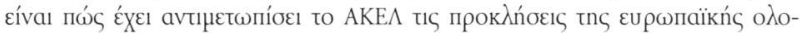

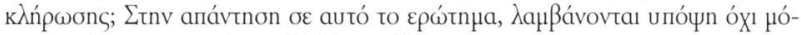

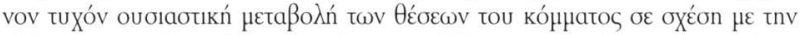

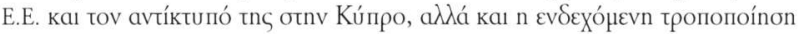

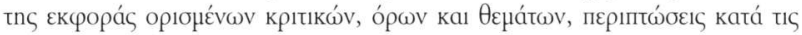

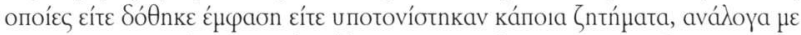

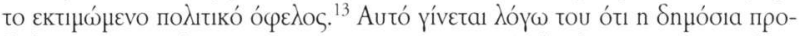

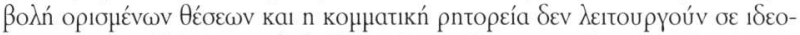

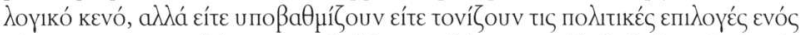

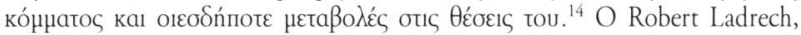

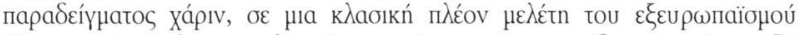

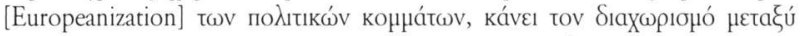

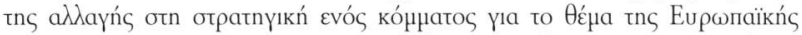

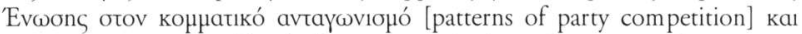

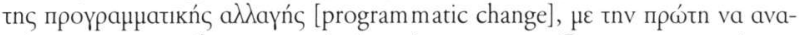

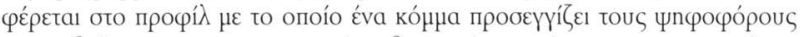

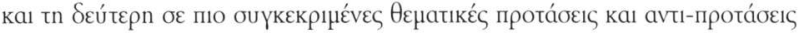

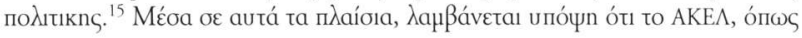

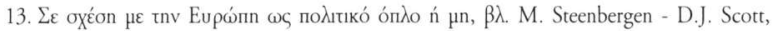
"Contesting Europe? The Salience of European Integration as a Party Issue", бо G. Marks -

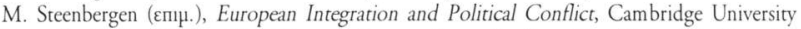
Press, Cambridge 2004, o. 165-192 kaı A. Batory, «Hungarian Party Identities and the Question of European Integration», Working paper 49, Sussex European Institute.

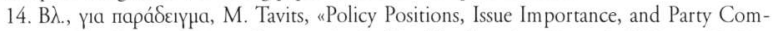
petition in New Democracies", Comparative Political Studies, tón. 41, тx. 1, 2008, o. 48-72.

15. R. Ladrech, "Europeanisation and Political Parties: Towards a Framework for Analysis»,

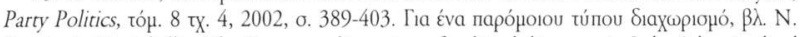
Conti - L. Verzichelli, "The European dimension of political discourse in Italy. A longitudinal analysis of party preferences (1950-2001)", Occasional papers of CIRCaP, Centre for the Study of Political Change, Siena 2003. B $\lambda$. eníonc G. Charalambous, «Realignment and Entrenchment: The Europeanisation of Rifondazione Comunistan, Perspectives on European Politics and Society, tóp. 12, тx. 1, 2011, б. 29-51. 


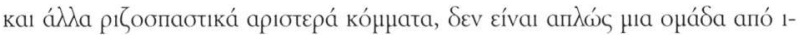

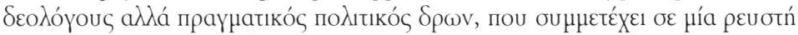

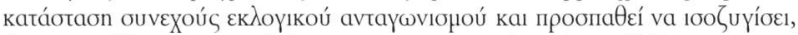

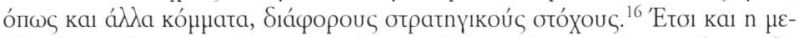

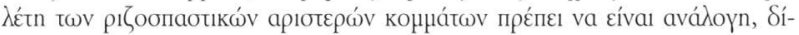

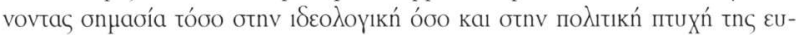

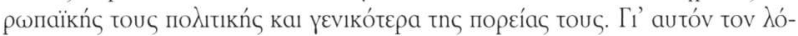

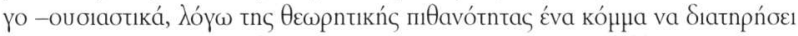

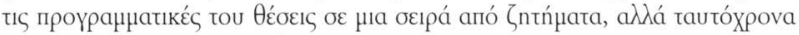

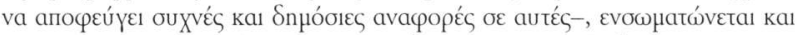

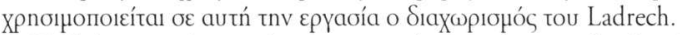

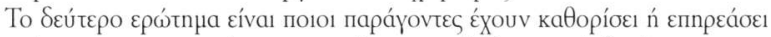

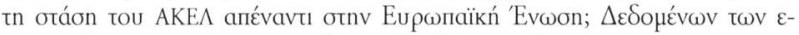

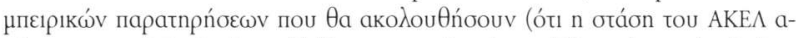

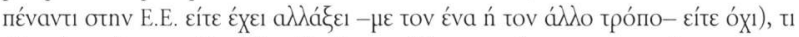

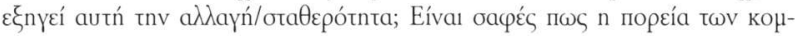

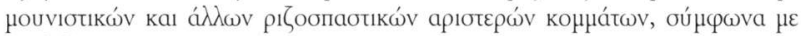

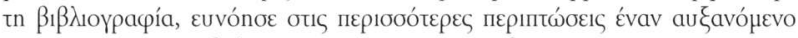

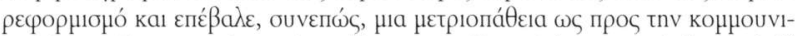

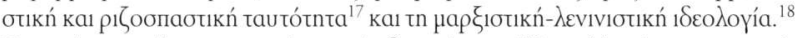

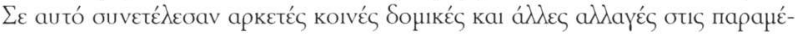

16. Гıа пара́бєıүна, T. Bale - R. Dunphy, «In from the Cold: Left Parties, Policy, Office and Votes in Advanced Liberal Democracies since 1989", paper presented at the 57th Political Studies Association Annual Conference, Bath UK, 2007.

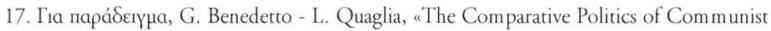
Euroscepticism in France, Italy and Spain", Party Politics, tóp. 3, tx. 4, 2007, o. 478-499' J. Botella - L. Ramiro, "The Crisis of West European Communist Parties and their Change Trajectories: Communists, Post-Communists, Ex-Communists», oto J. Botella - L. Ramiro ( $\varepsilon-$ пाц.), The Crisis of Communism and Party Change: The Evolution of West European Com-

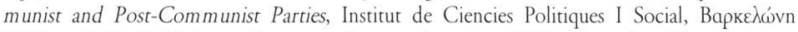
2003, o. $248^{\circ}$ K. Hudson, European Communism since 1989: Towards a New European Left?, Palgrave, Basingstoke $2000^{\circ}$ D. Sassoon, «Fin-de-Siècle Socialism: The United Modest

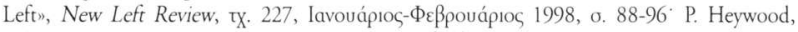
"The West European Communist Movement: Of Chance and Death and Mutability", oro M.J. Bull - P. Heywood (впц.), West European Communist Parties After the Revolutions of 1989, Macmillan, Aovoívo 1994, o. xviii' R. N. Tannahill, The Communist Parties of Western

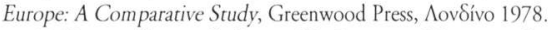

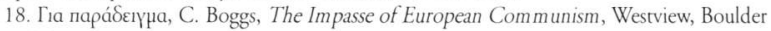
Co. 1982. 


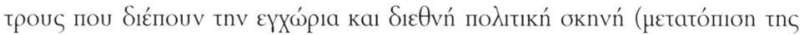

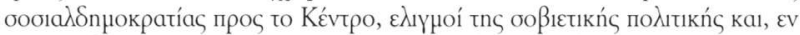

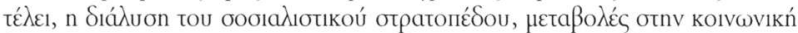

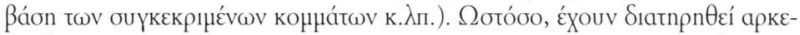

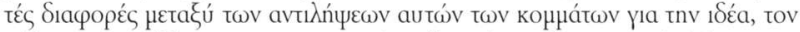

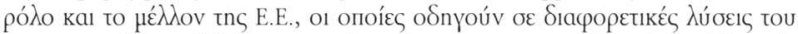

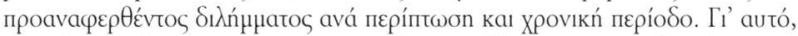

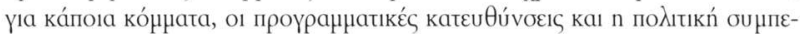

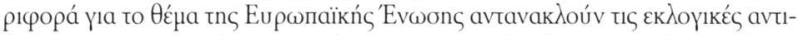

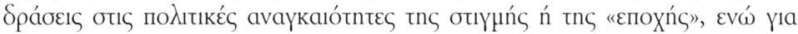

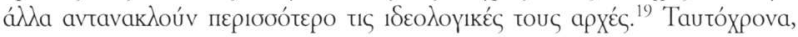

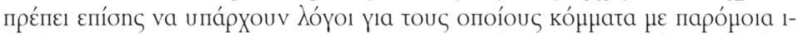

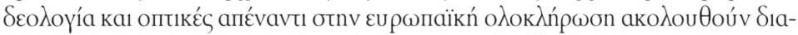

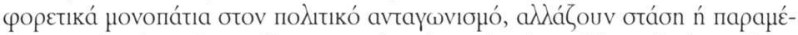

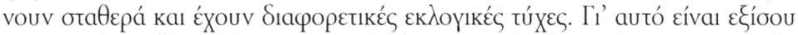

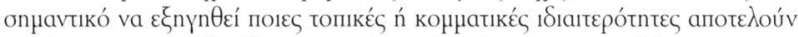

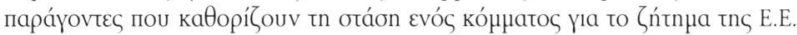

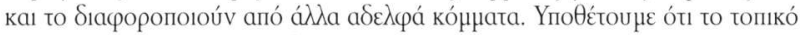

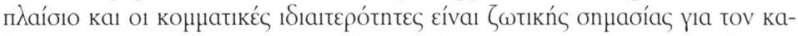

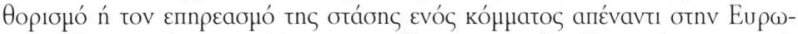

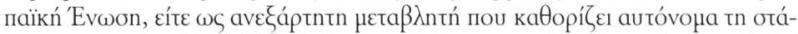

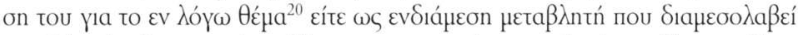

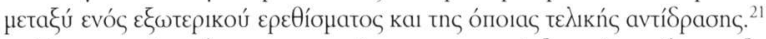

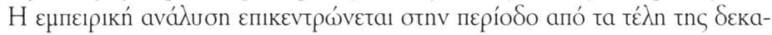

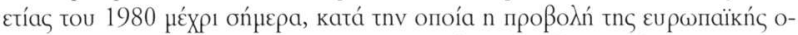

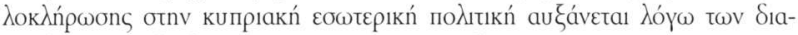

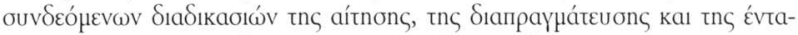

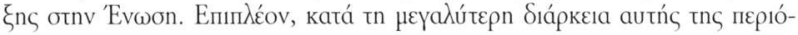

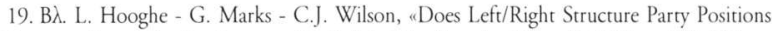
on European Integration?», Comparative Political Studies, tó $\mu .35$, тx. 8, 2002, о. 965-989 kaı G. Charalambous, «Realignment and Entrenchment: The Europeanisation of Rifondazione Comunista", ó.n.

20. B $\lambda$. K. Johansson - T. Raunio, «Partisan Responses to Europe: Comparing Finnish and Swedish Political Parties", European Journal of Political Research, tóp. 39, tx. 2, 2011, o. 225-49.

21. B $\lambda$. R. Ladrech, «Europeanization and political parties", Living Reviews in European

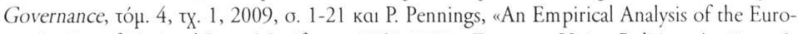
peanization of National Party Manifestos, 1960-2003w, European Union Politics, tóp. 7, тx. 2, 2006, б. 257-270. 


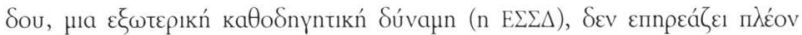

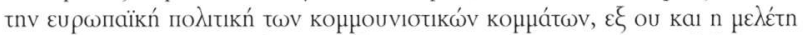

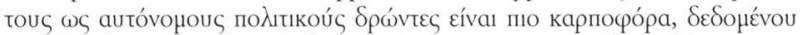

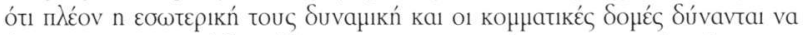

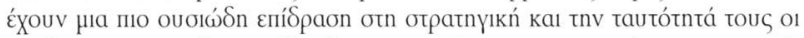

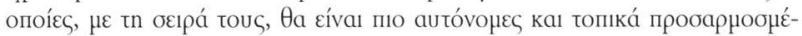

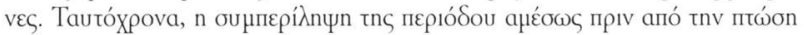

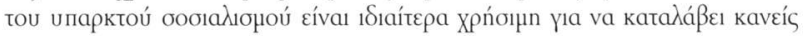

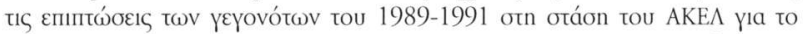

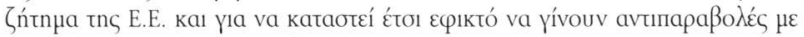

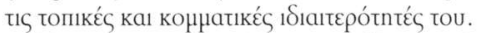

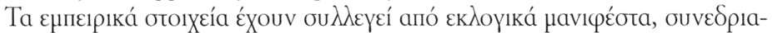

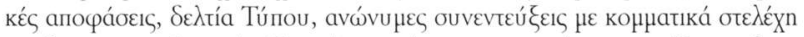

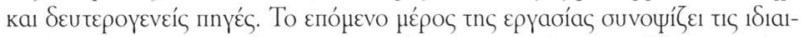

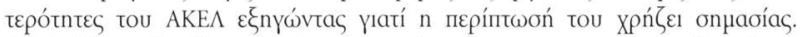

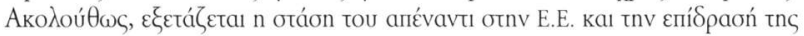

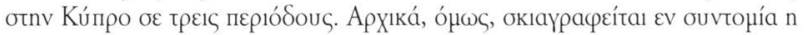

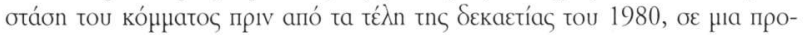

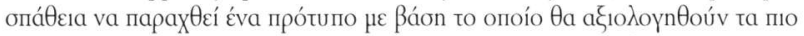

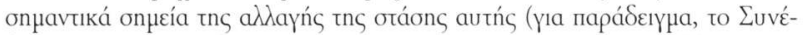

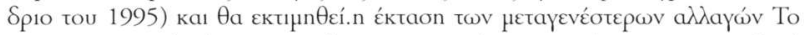

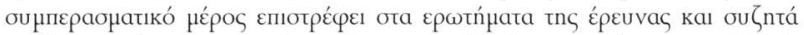

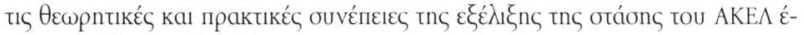

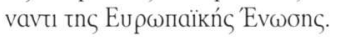

\section{H ПIEPIIT $\Omega$ SH TOY AKE $\Lambda$}

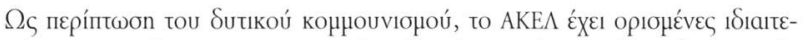

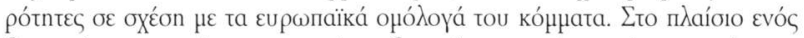

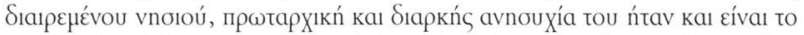

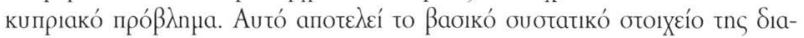

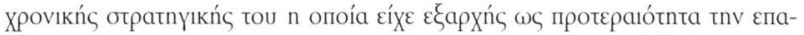

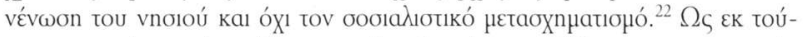

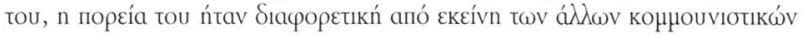

22. G. Charalambous, "AKEL: un profile socio-politique", oto J.-M. De Weale - D.-L. Seiler (впц.), Les Partis de la Gauche Anticapitaliste en Europe, Econom ica, Парі́r 2011. 


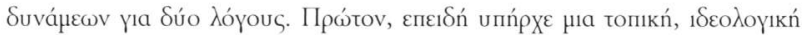

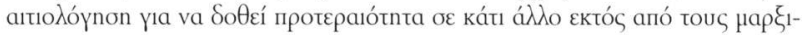
отькоú

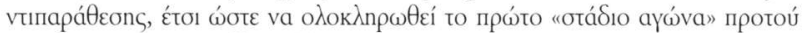

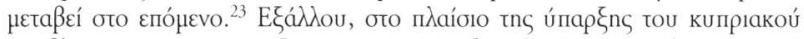

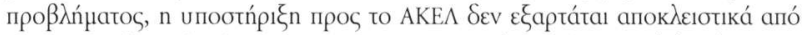

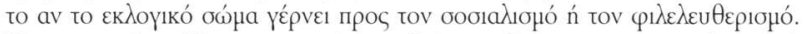

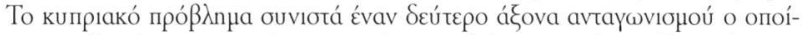

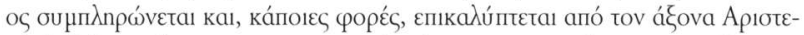

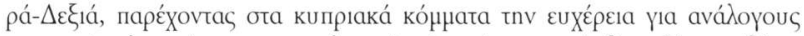

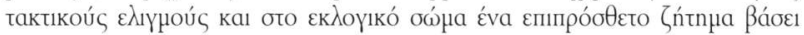

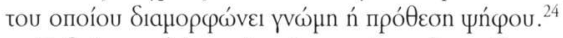

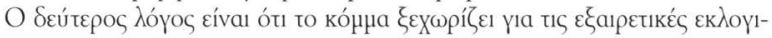

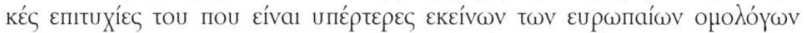

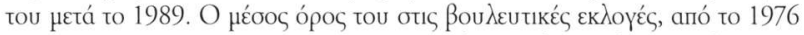

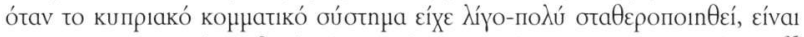

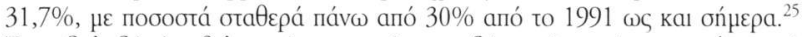

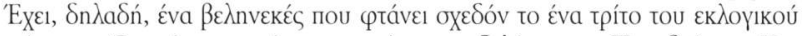

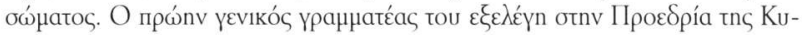

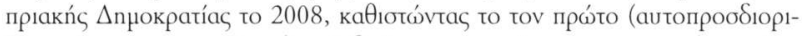

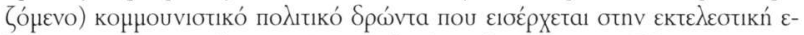

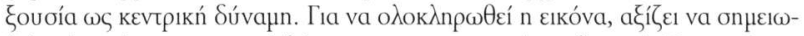

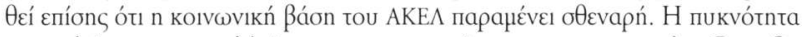

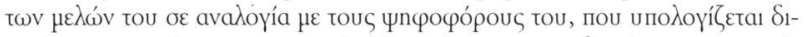

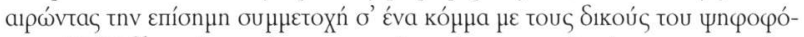

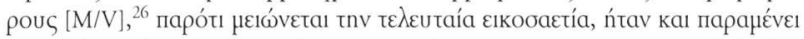

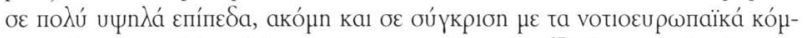

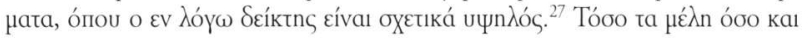

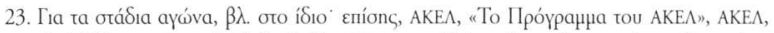

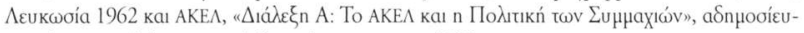

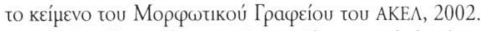

24. C. Christophorou, "Party Change and development in Cyprus (1995-2005)», South European Society \& Politics, tóp. 11, тx. 3-4, 2005, б. 513-542.

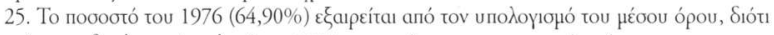

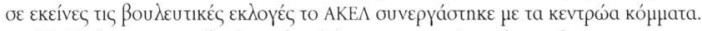

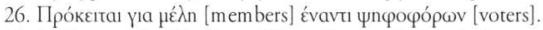

27. A. Bosco - L. Morlino, "What Changes in South European Parties? A Comparative Introduction", South European Society and Politics, tó $\mu .11$, тx. 3, 2006, o. 331-358. 


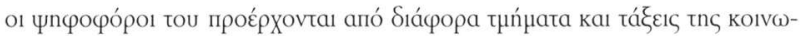

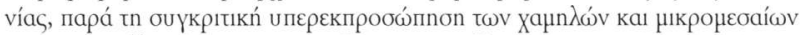

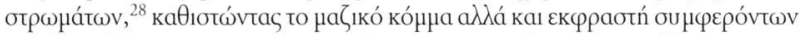

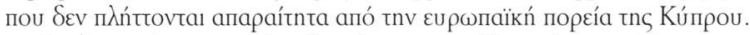

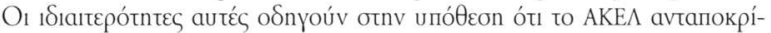

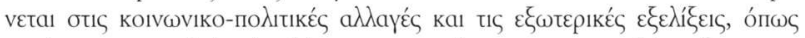

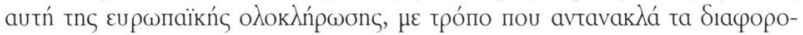

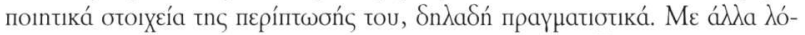

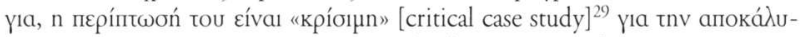

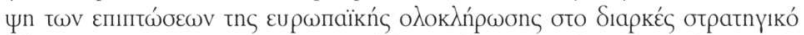

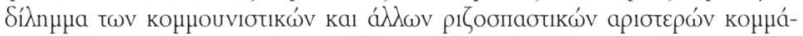

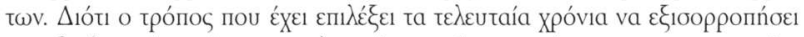

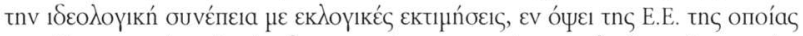

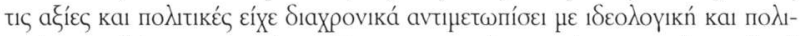

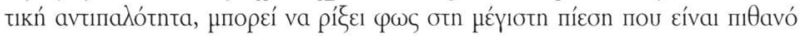

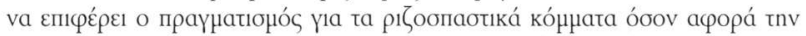

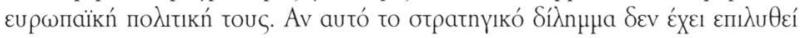

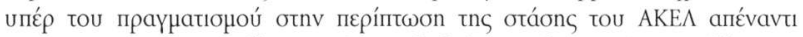

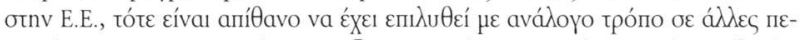

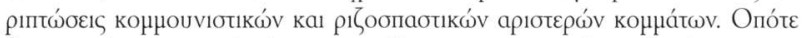

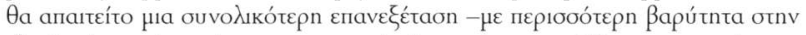

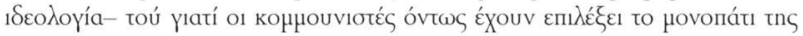

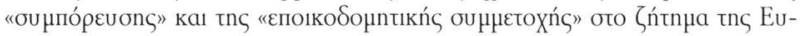
pwпаїкńs 'Evwons.

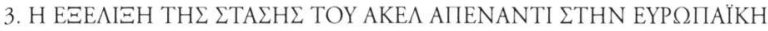 $\mathrm{EN} \Omega \Sigma \mathrm{H}$}

\section{a, Пріv anó to 1990}

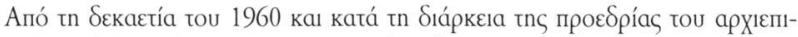

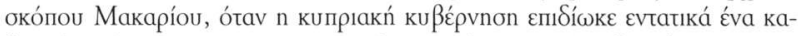

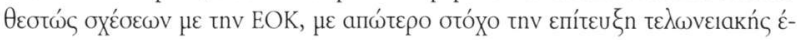

28. G. Charalambous, «AKEL: Un Profile Socio-politique», ó.m.

29. Bג. B. Flyvjberg, "Five Misunderstandings about Case-Study Research", Qualitative Inquiry, tóp. 12, тх. 2, 2006, б. 219-245. 


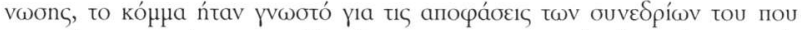

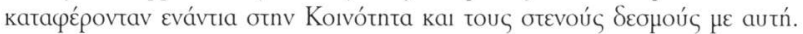

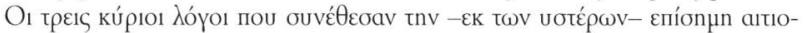

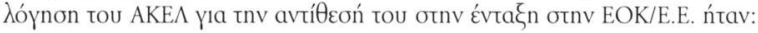

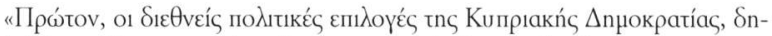

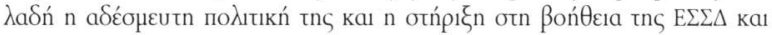

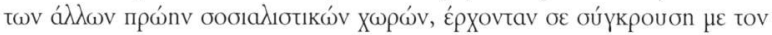

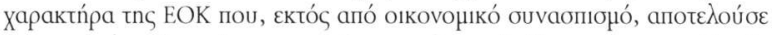

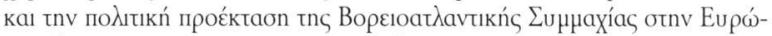

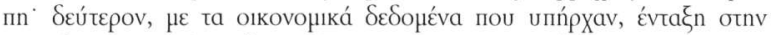

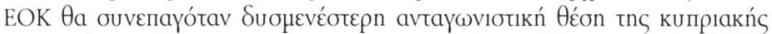

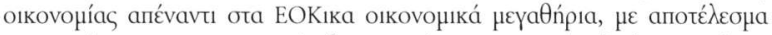

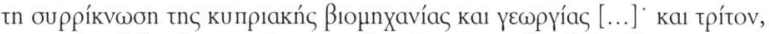

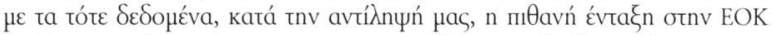

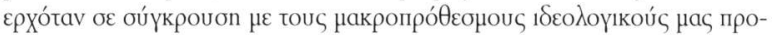

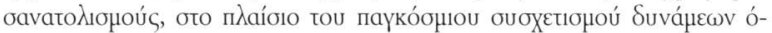

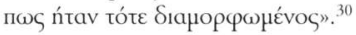

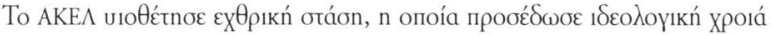

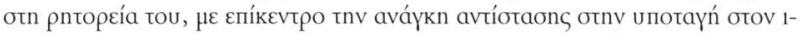

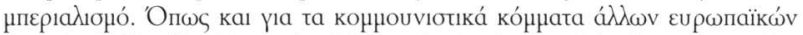

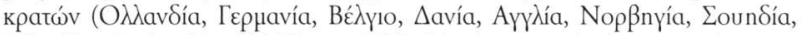

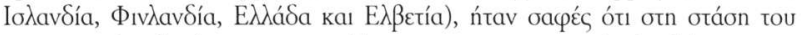

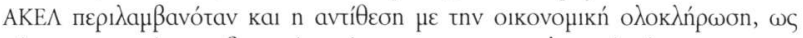

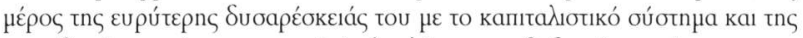

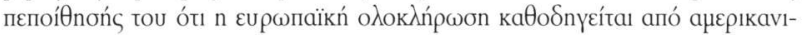

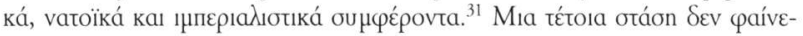

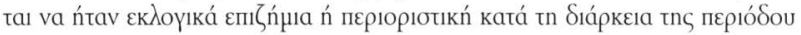

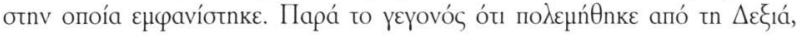

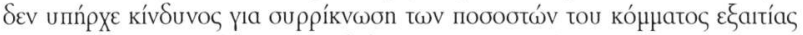

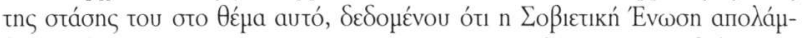

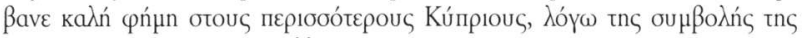

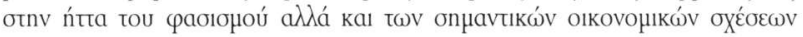

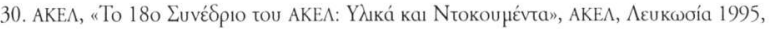
๙. 41 .

31. N. McInnes, The Communist Parties of Western Europe, Oxford University Press,

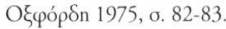




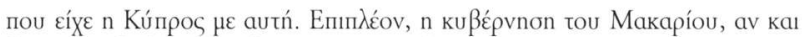

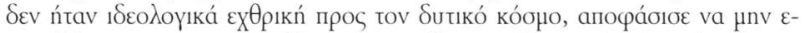

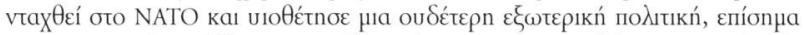

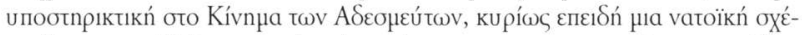

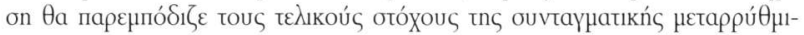

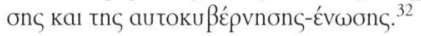

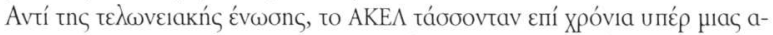

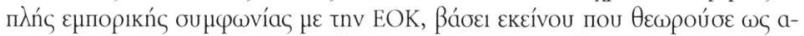
vanó

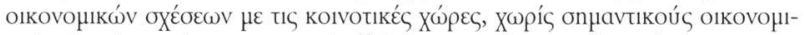

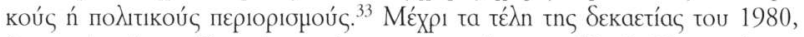

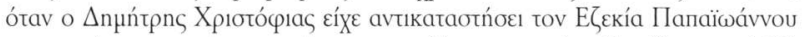

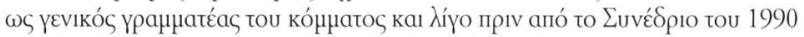

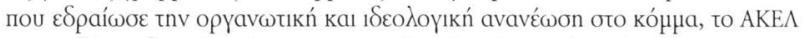

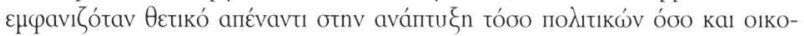

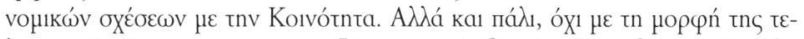

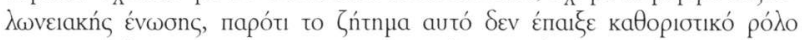

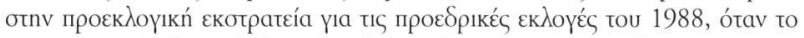

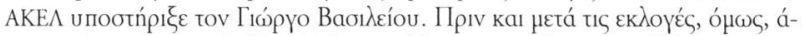

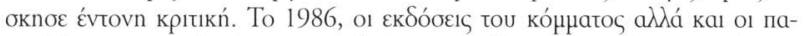

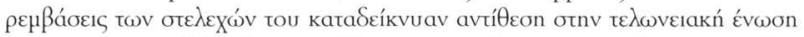

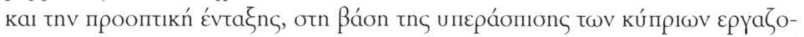

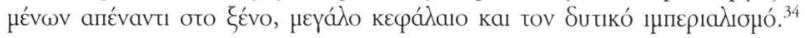

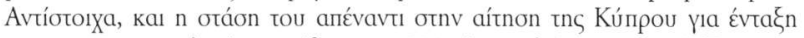

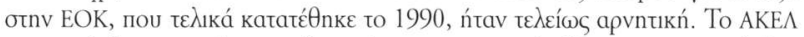

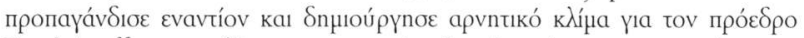

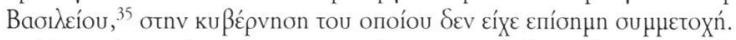

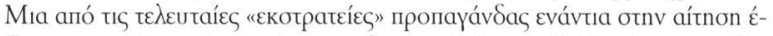

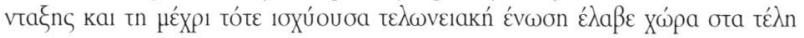

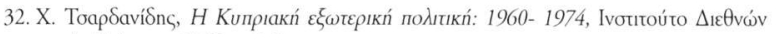

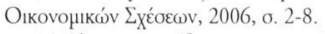

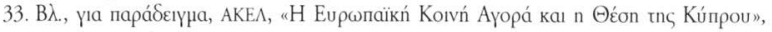

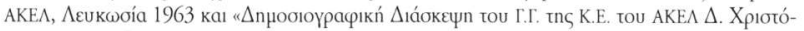

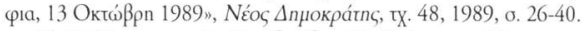

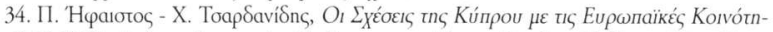

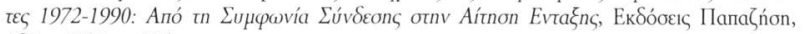
A日ńva 1991, o. 234.

35. Eto ísıo, o. $342,374$. 


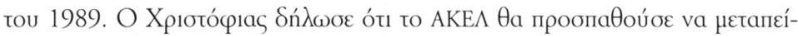

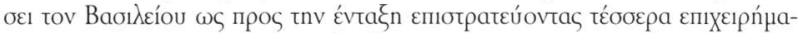

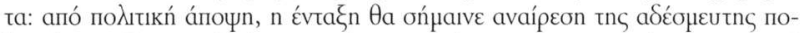

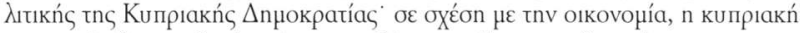

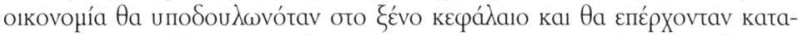

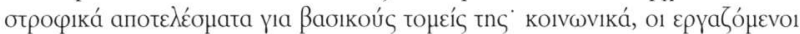

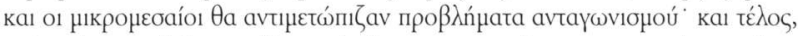

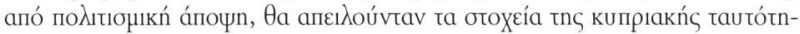

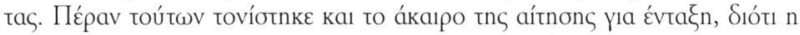

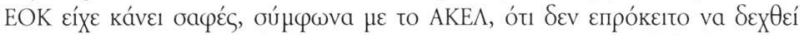

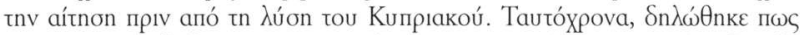

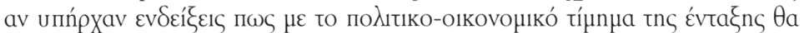

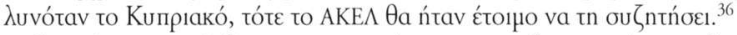

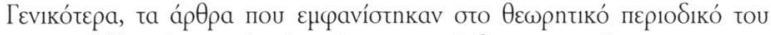

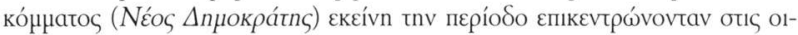

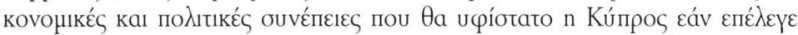

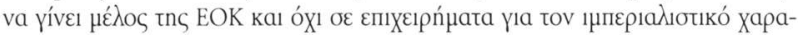

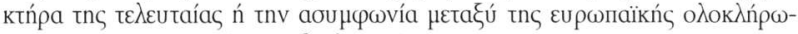

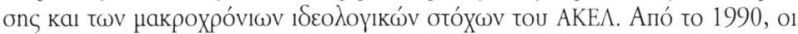

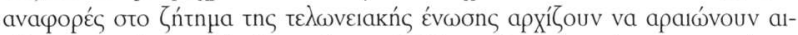

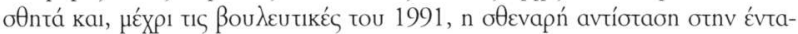

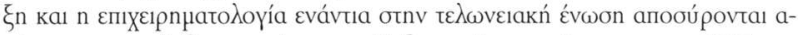

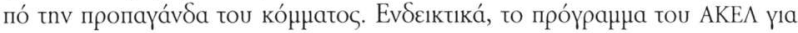
тІৎ ßou

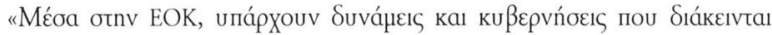

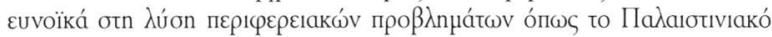

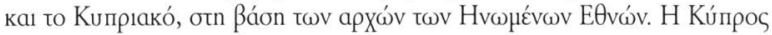

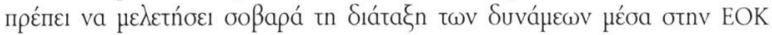

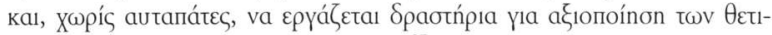

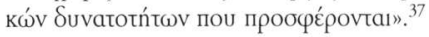

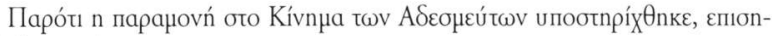

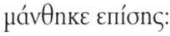

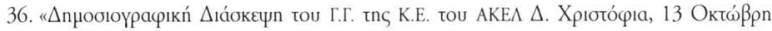
1989", о́.п., о. 26-28.

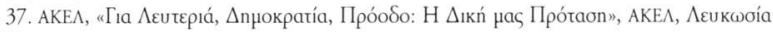
1991. 


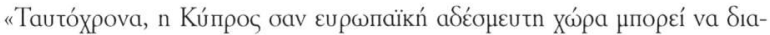

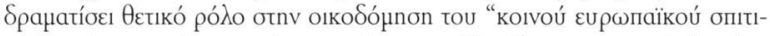

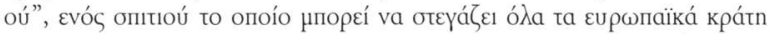

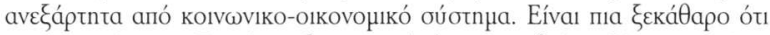

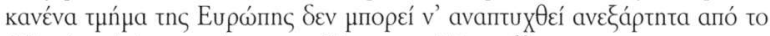

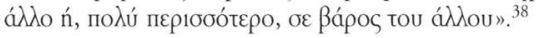

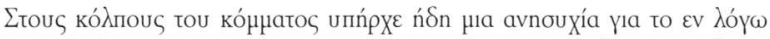

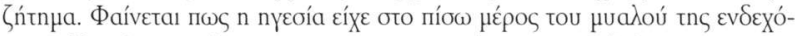

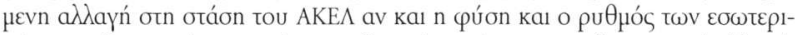

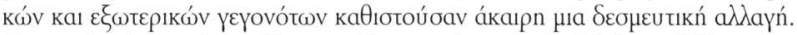

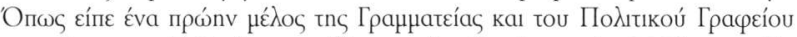

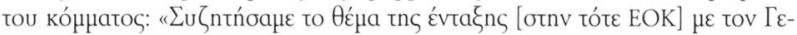

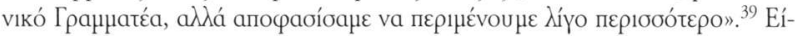

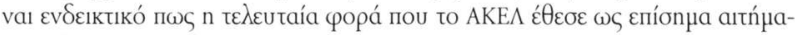

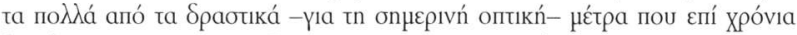

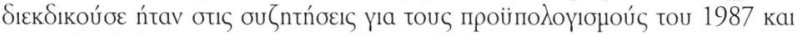

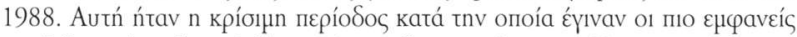

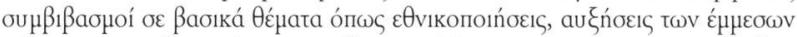

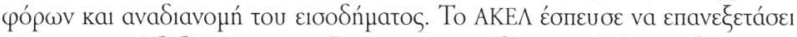

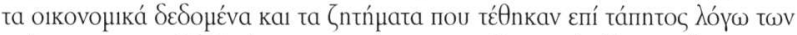

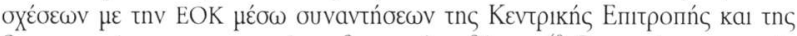
Sn

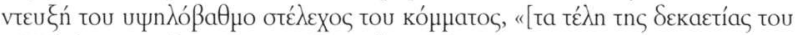

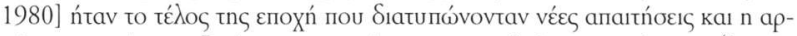

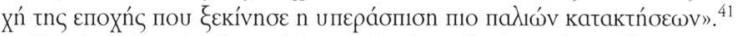

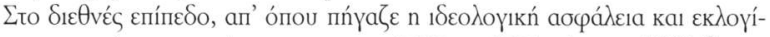

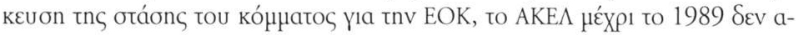

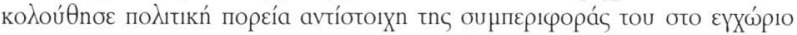

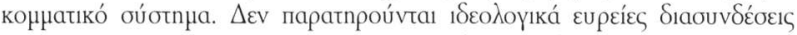

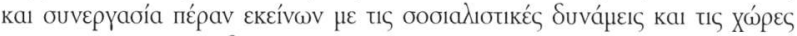

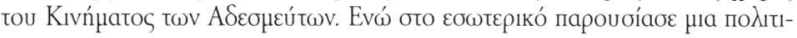

\section{8. ¿ to ísı.}

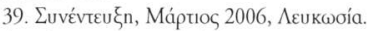

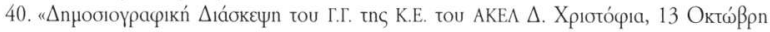
1989», о́. п., о. 34.

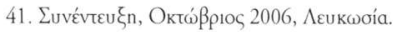




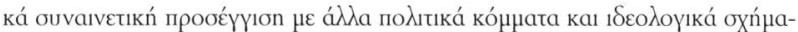

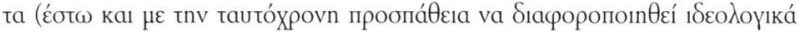
anó ó

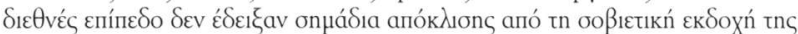

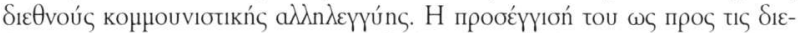

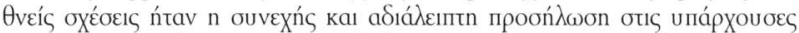

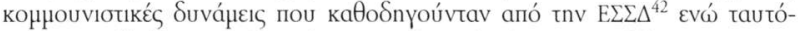

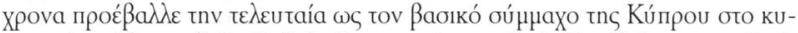

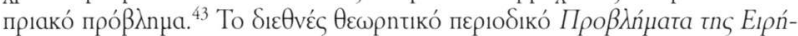

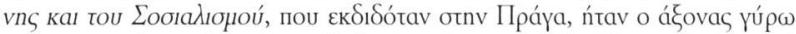

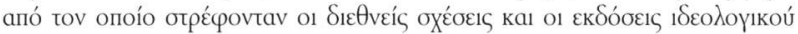

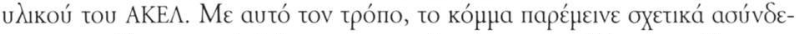

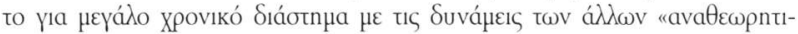

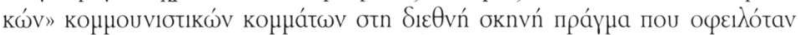

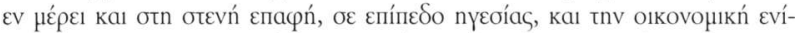

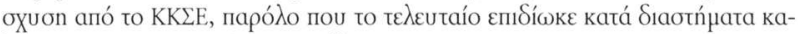

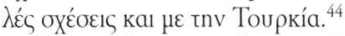

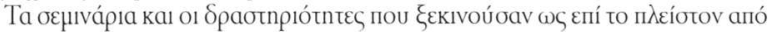

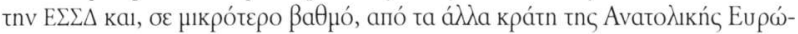

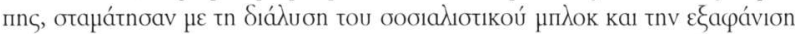

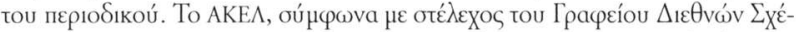

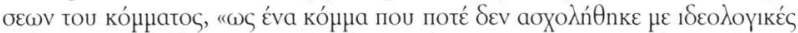

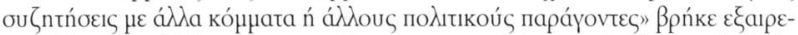

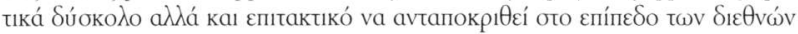

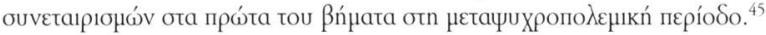

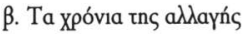

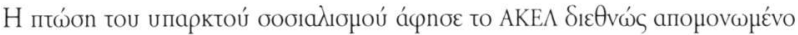

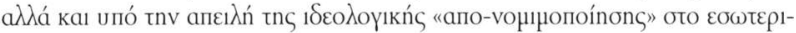

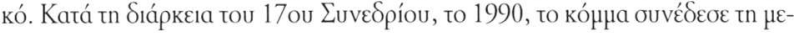

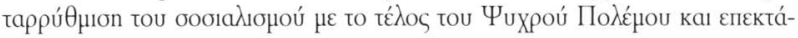

42. B $\lambda$. T.W. Adams, AKEL: The Communist Party of Cyprus, Hoover Institution Press, Kà̀ı́́pvia 1971, б. 156-179.

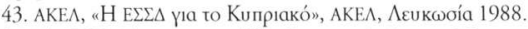

44. B $\lambda$. T.W. Adams, AKEL: The Communist Party of Cyprus, ó.п.

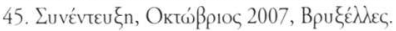




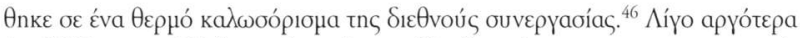

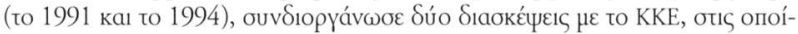

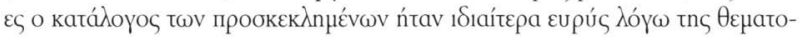

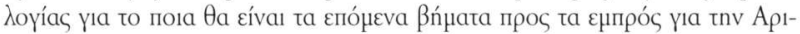

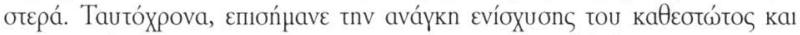

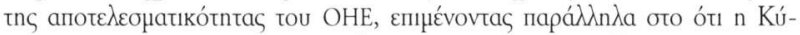

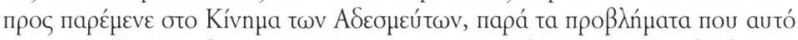

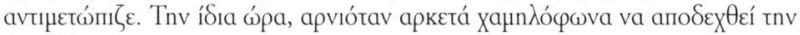
Évtaß́n tns otnv EOK.

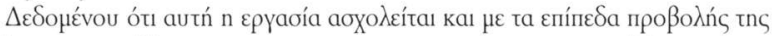

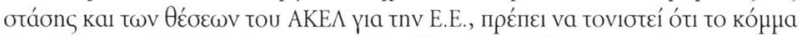

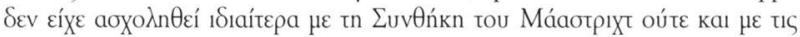

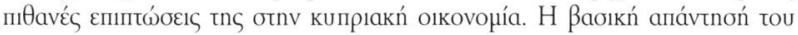

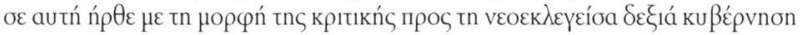

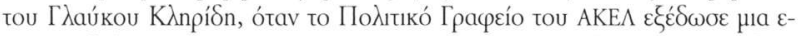

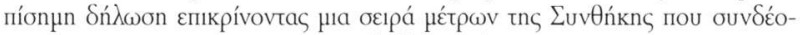

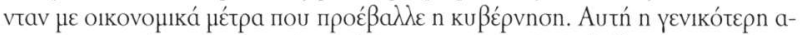

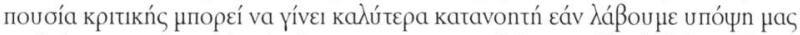

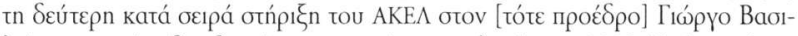

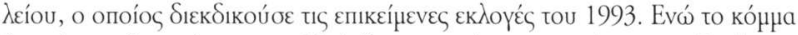

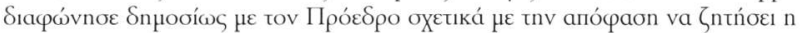

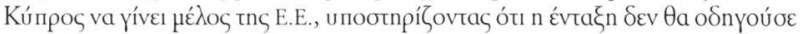

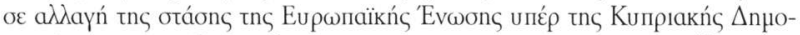

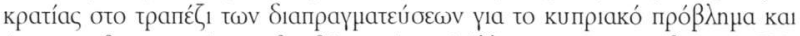

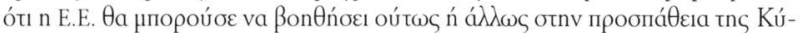

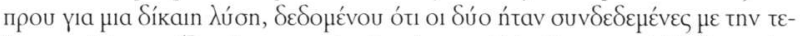

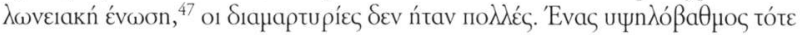

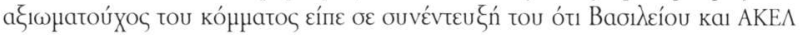

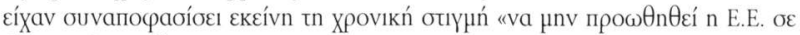

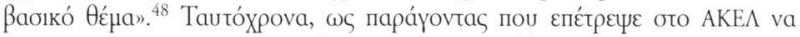

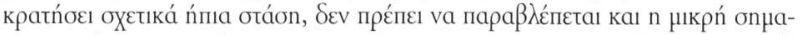

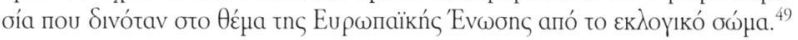

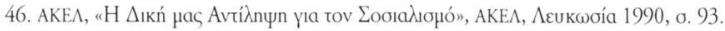

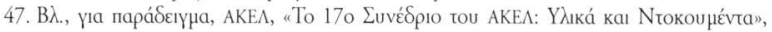

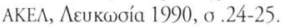

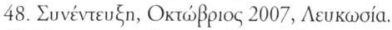

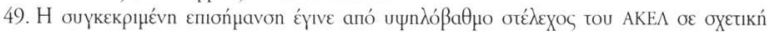




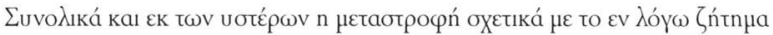

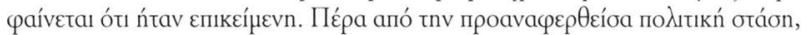

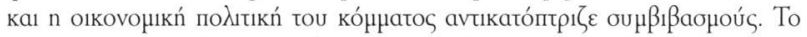

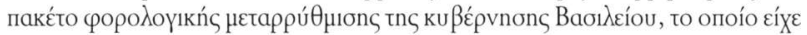

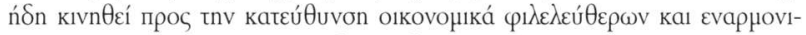

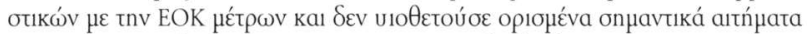

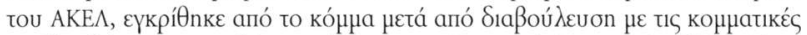

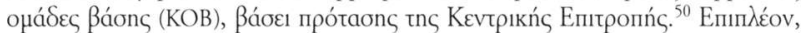

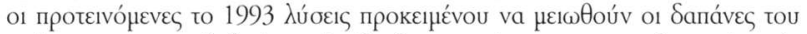

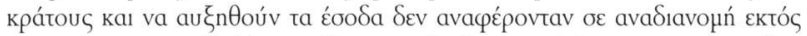

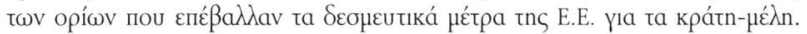

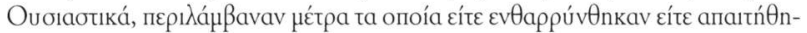

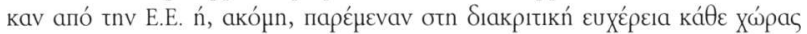

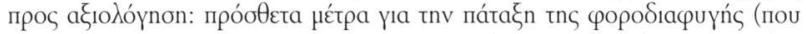

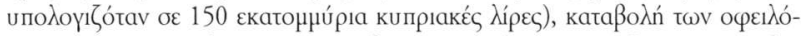

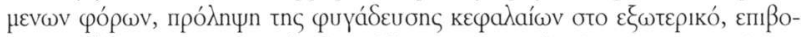

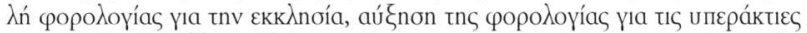

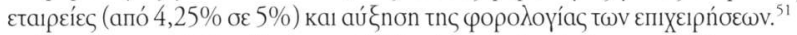

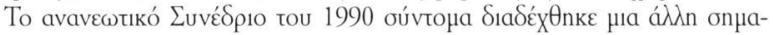

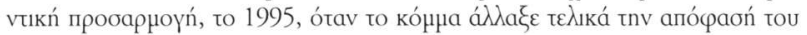

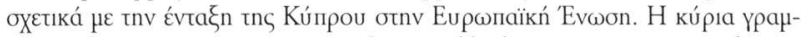

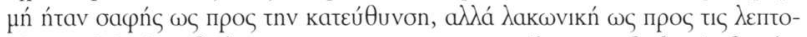

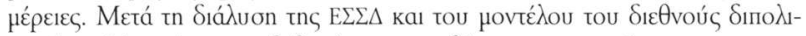

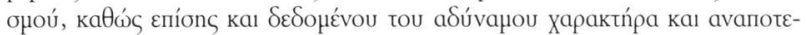

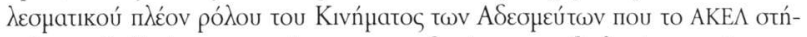

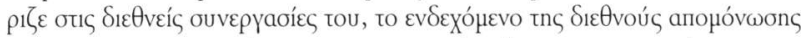

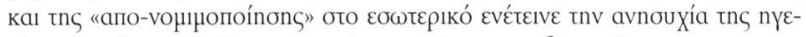

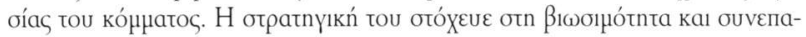

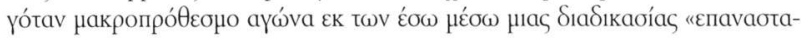

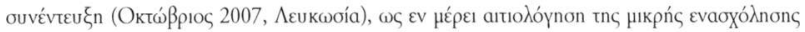

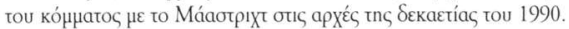

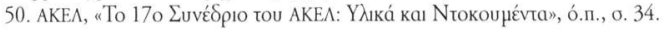

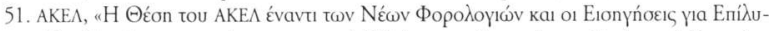

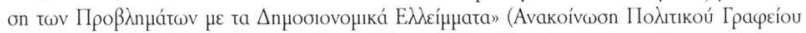

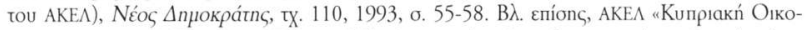

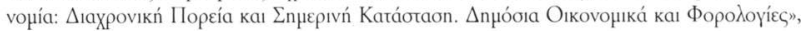

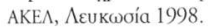




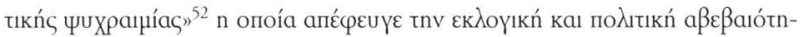

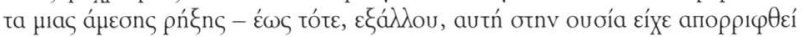

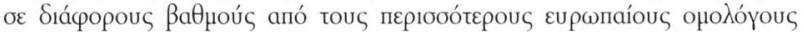

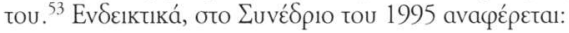

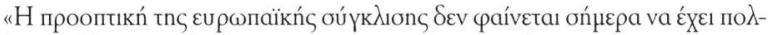

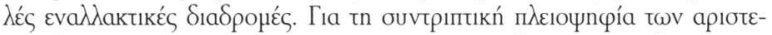

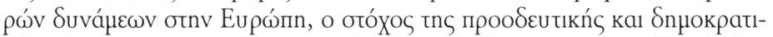

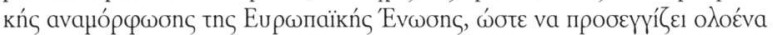

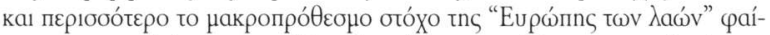

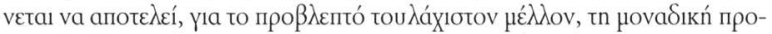
оптки́n. ${ }^{54}$

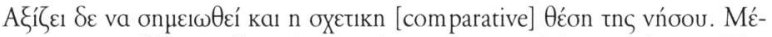

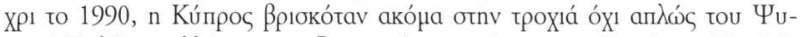

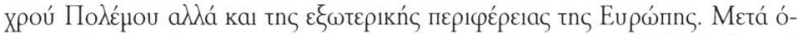

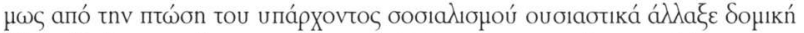

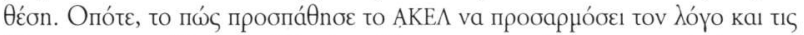

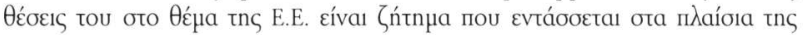

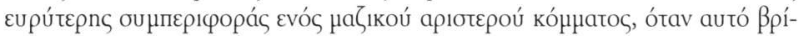

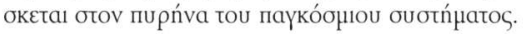

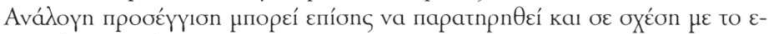

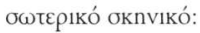

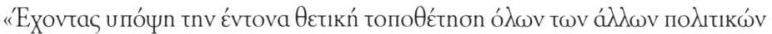

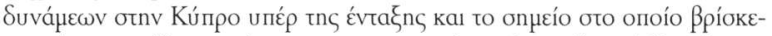

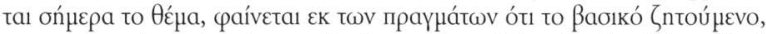

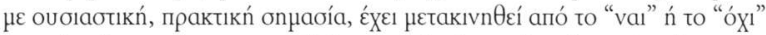

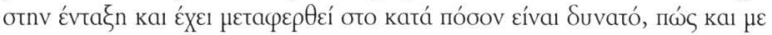

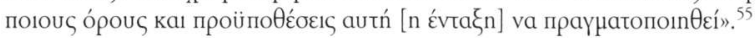

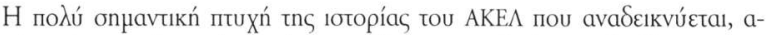

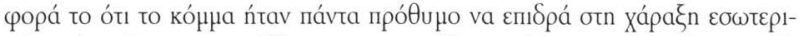

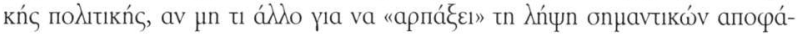

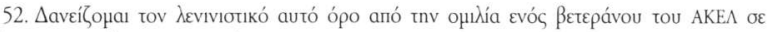

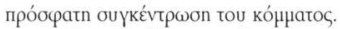

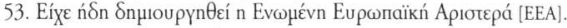

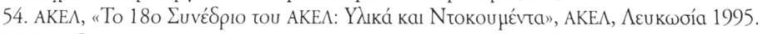

55. ¿to í́10. 


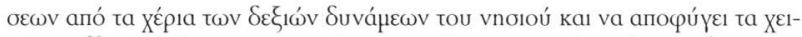

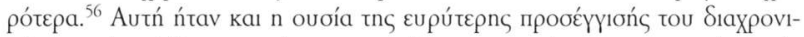

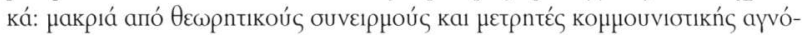

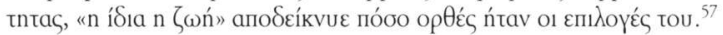

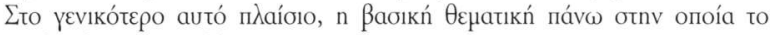

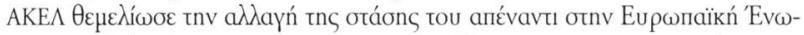

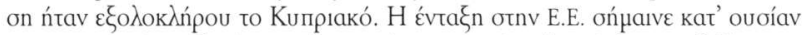

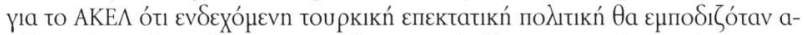

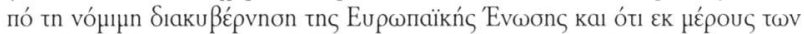

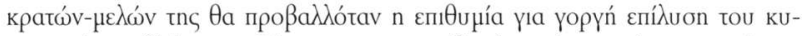

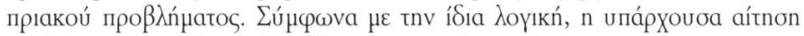

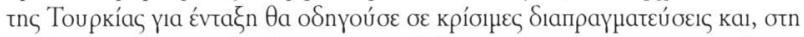

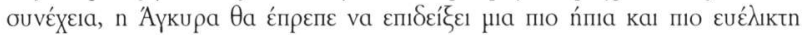

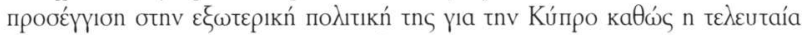

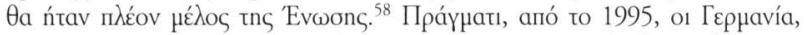

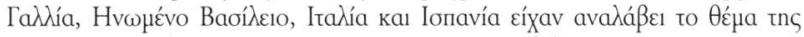

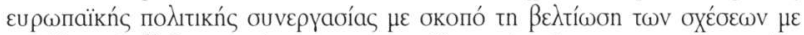

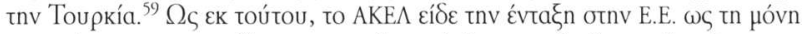

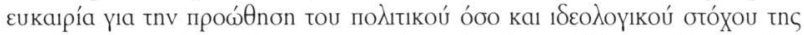

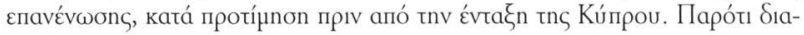

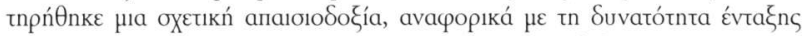

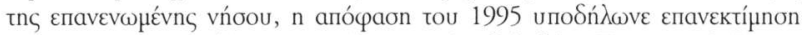

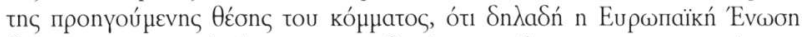

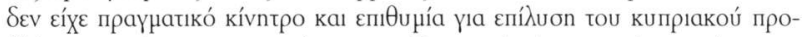

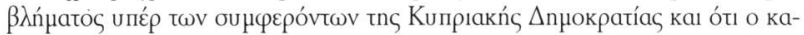

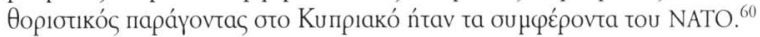

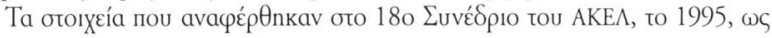

56. G. Charalambous, "The Strongest Communists in Europe: Accounting for AKEL's Electoral Successin, Journal of Communist Studies and Transition Politics, tóp. 23, тx. 3, 2007, б. 438.

57. N. Peristianis, "The Rise of the Left and of the Intra-Ethnic Cleavage», бто $\mathrm{H}$. Faustmann - N. Peristianis (впи.), Britain in Cyprus: Colonianism and Post Colonianism 1878-2006, Bibliopolis, Mannheim 2006, о. 260.

58. G. Charalambous, "The Strongest Communists in Europe: Accounting for AKEL's Electoral Success", ó.n., o. 437.

59. C. Brewin, The European Union and Cyprus, Eothen, Cambridgeshire 2000, o. 18.

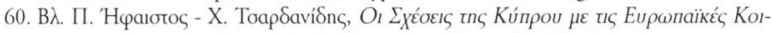

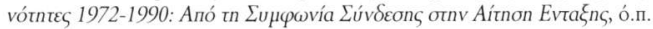




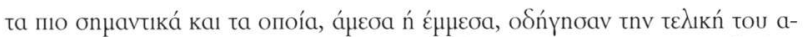

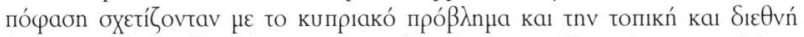

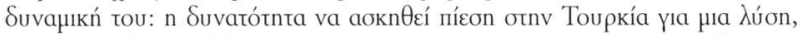

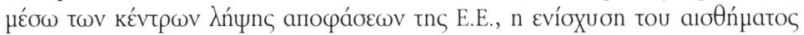

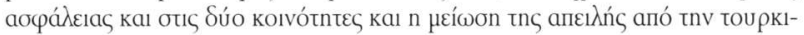

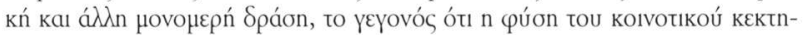

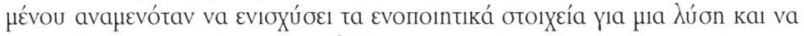

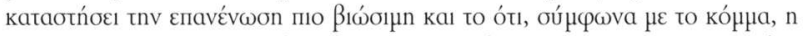

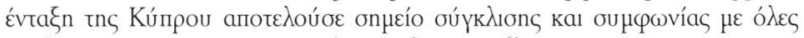

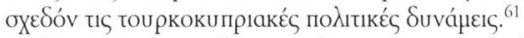

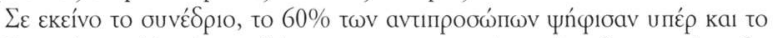

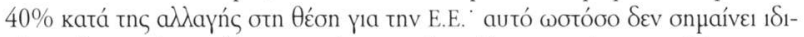

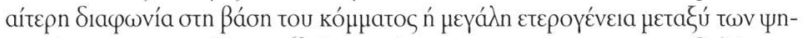

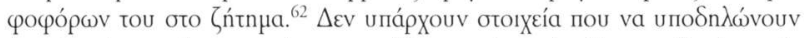

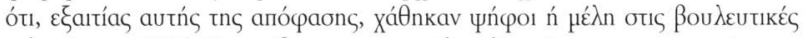

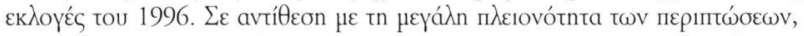

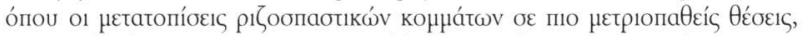

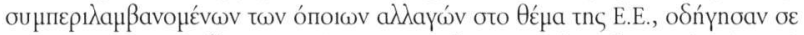

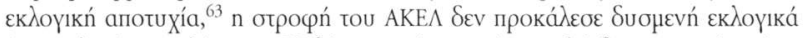

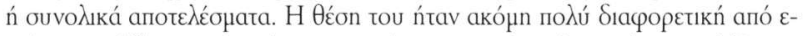

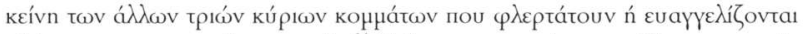

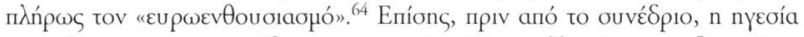

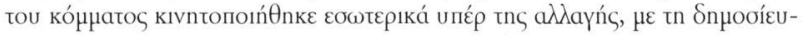

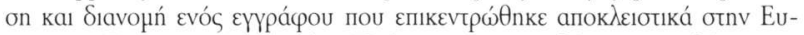

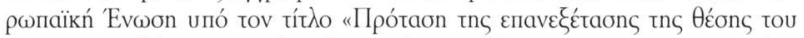

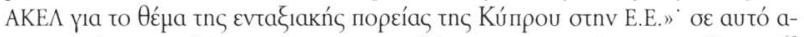

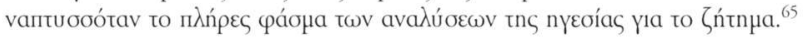

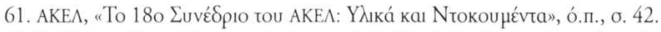

62. I. Katsourides, «Europeanisation and Political Parties in Accession Countries: The Political Parties of Cyprus», Paper presented for the EpsNet Plenary Conference, Пapír 2003.

63. J. Adams - M. Clark - L. Ezrow - G. Glasgow, "Are Niche Parties Fundamentally Different from Mainstream Parties?: The Causes and Electoral Consequences of Western European Parties' Policy Shifts, 1976-98", American Journal of Political Science, tóp. 50, тx. 3, 2006, о. 513-529.

64. B $\lambda$. I. Katsourides, "Europeanisation and Political Parties in Accession Countries: The Political Parties of Cyprus», ó.п.

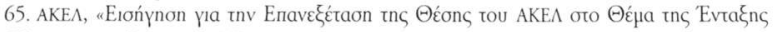

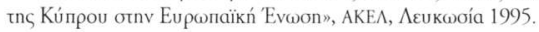




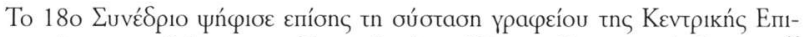

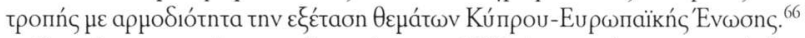

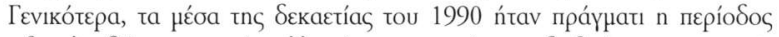

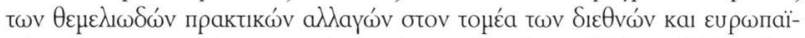

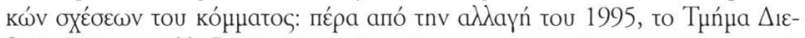

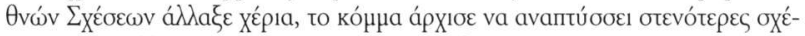

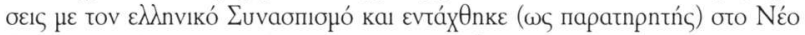

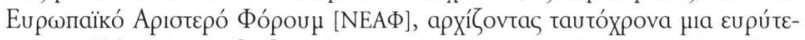

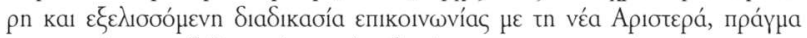

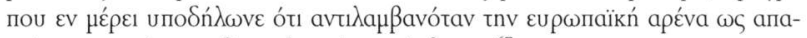

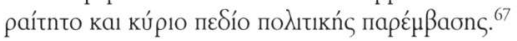

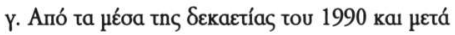

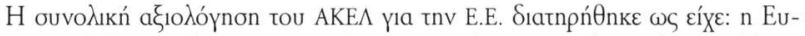

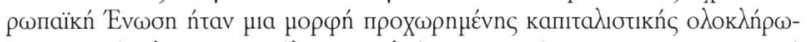

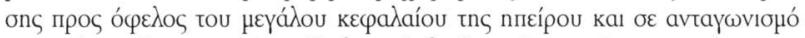

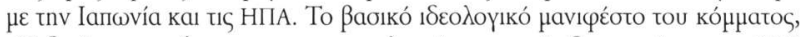

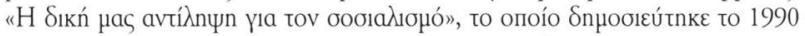

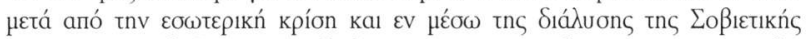

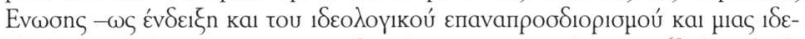

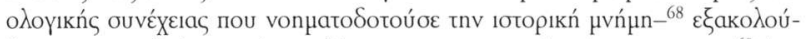

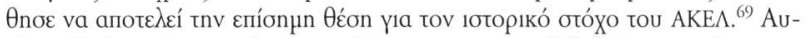

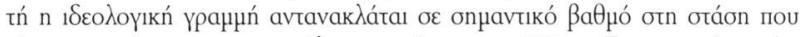

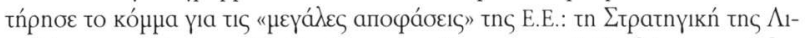

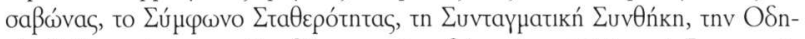

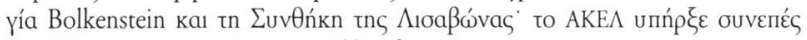

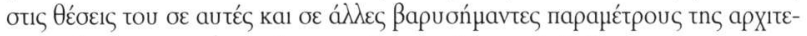

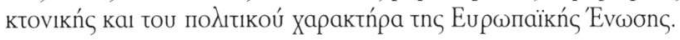

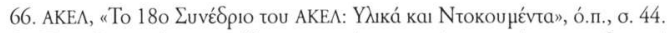

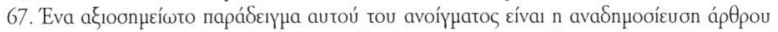

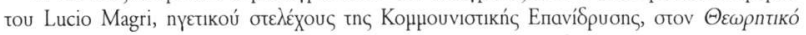

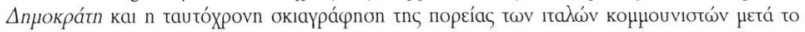

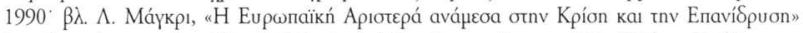

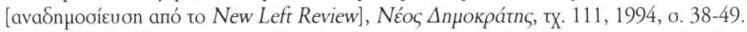

68. Bג. G. Charalambous, «The Strongest Communists in Europe: Accounting for AKEL's Electoral Success", о́.п., о. 435-436.

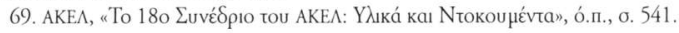




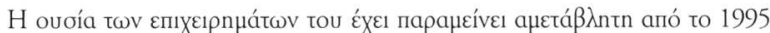

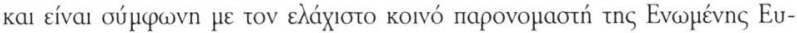

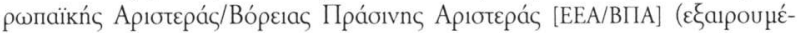

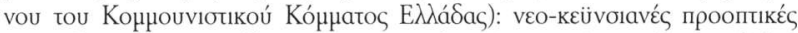

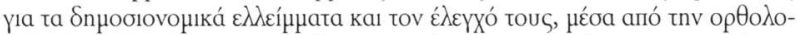

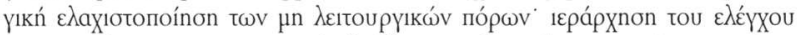

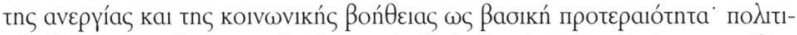

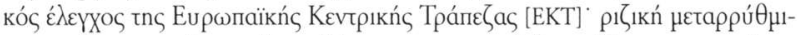

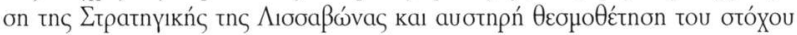

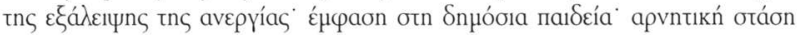

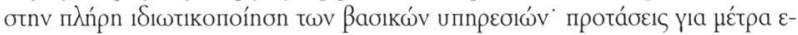

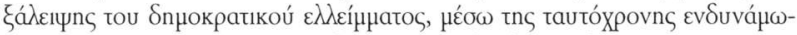
on

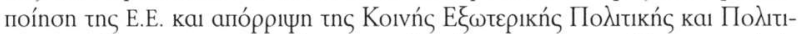

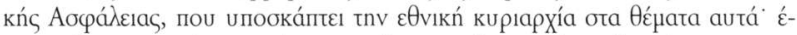

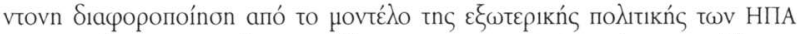

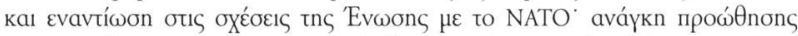

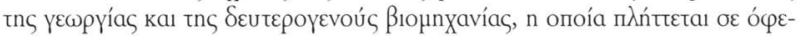

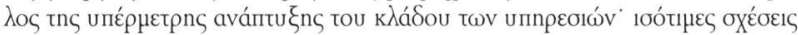

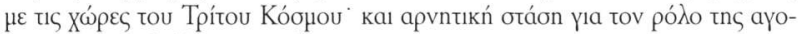

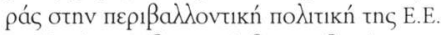

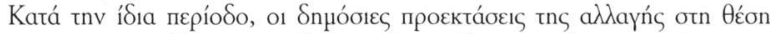

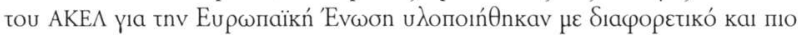

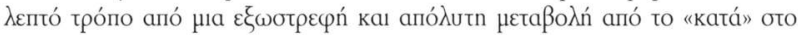

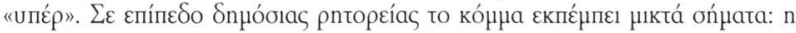

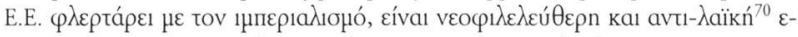

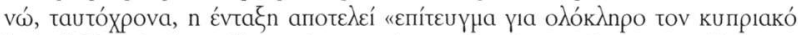

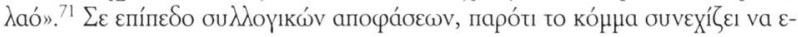

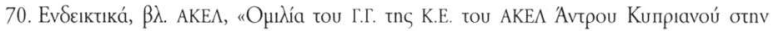

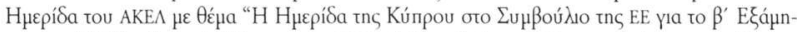

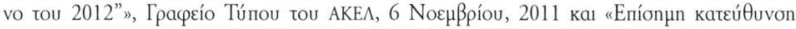

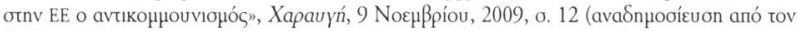
PI广oonáorn).

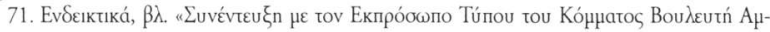

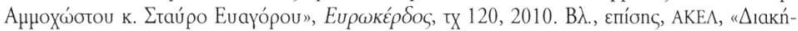

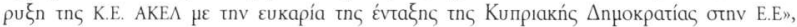
www.akel.org.cy, 2004. 


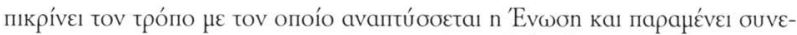

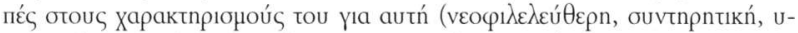

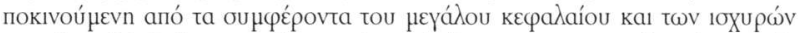

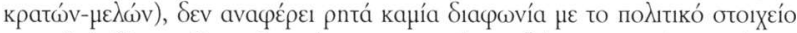

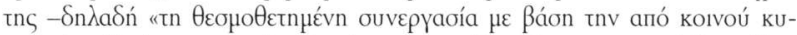

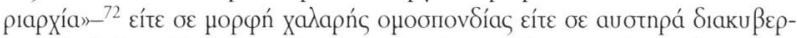

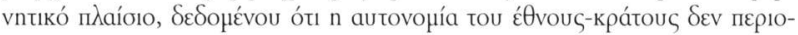

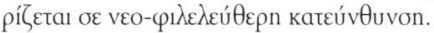

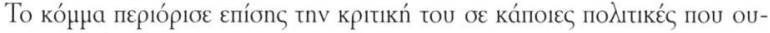

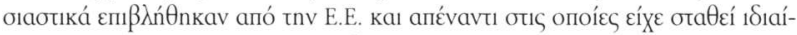

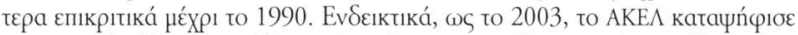

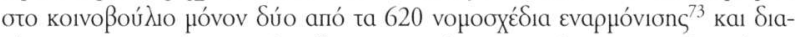

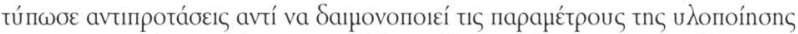

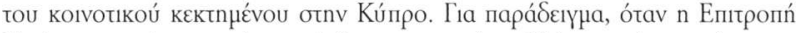

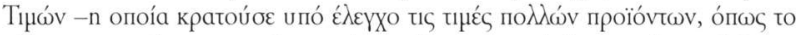

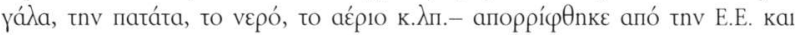

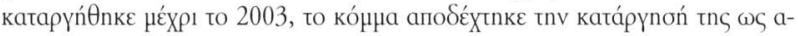

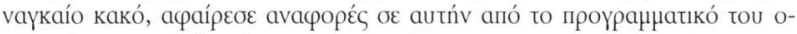

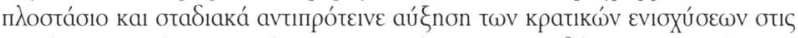

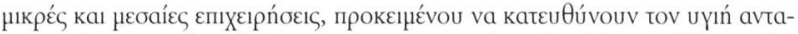

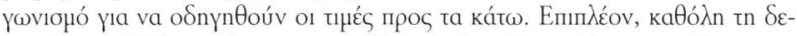

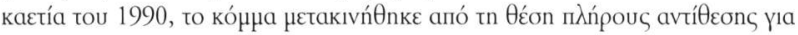

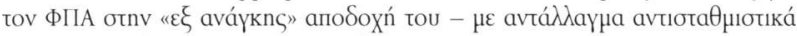

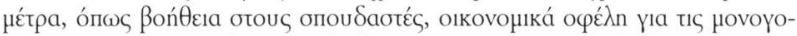

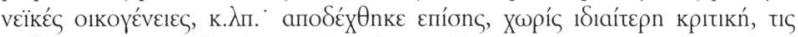

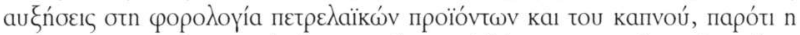

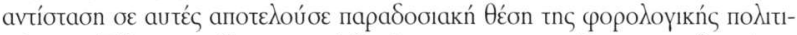

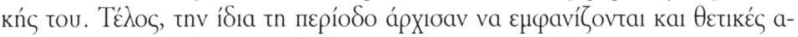

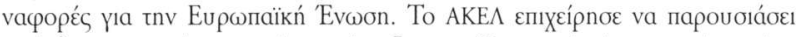

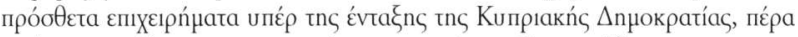

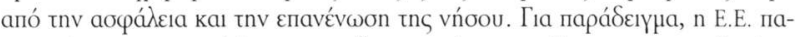

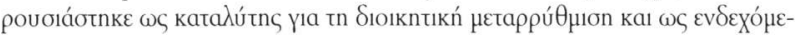

72. P. Kopecky - C. Mudde, «The two sides of Euroscepticism: Party Positions on European Integration in East and Central Europen, European Union Politics, tón. 3, тх. 3, 2002, б. 297-326.

73. I. Katsourides, «Europeanisation and Political Parties in Accession Countries: The Political Parties of Cyprus», ó.n. 


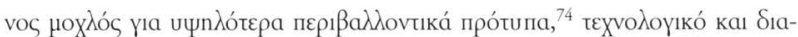

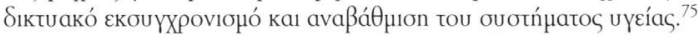

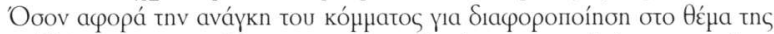

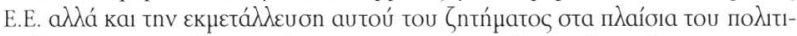

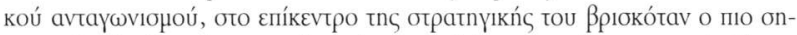

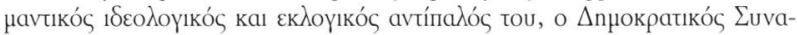

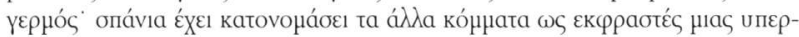

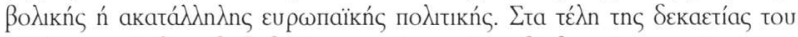

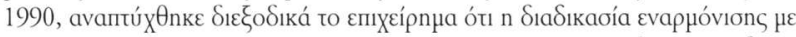

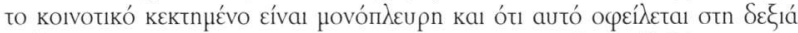

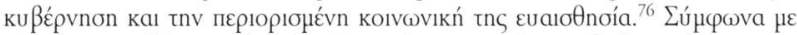

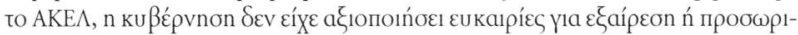

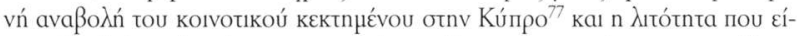

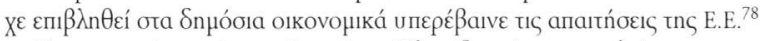

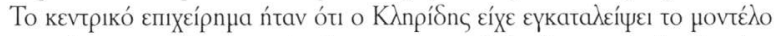

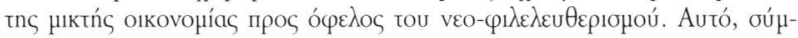

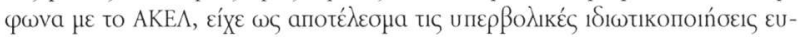

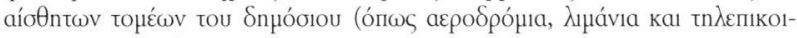

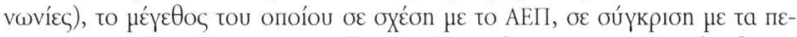

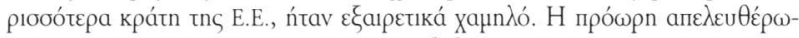

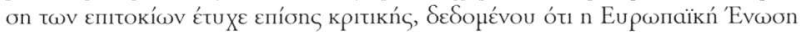

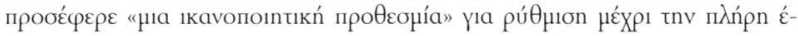

\section{4. ¿тo í́10.}

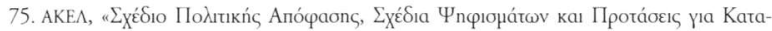

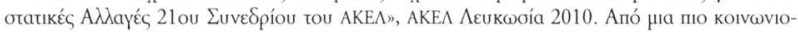

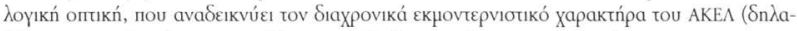

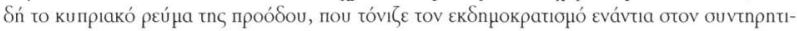
оцо́ ка тоv $\varepsilon Ө$ vıкıоно́ - $\beta \lambda$. A. Panayiotou, «Lenin in the Coffee-shop: the Communist Alternative and forms of non-western modernity", Postcolonial Studies, tón. 9, тx. 3, 2006, o.

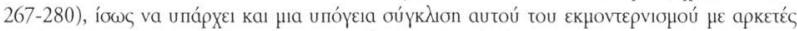

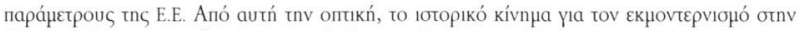

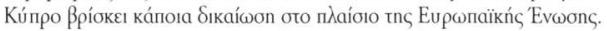

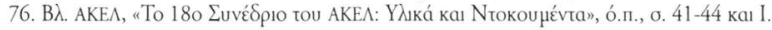
Katsourides, «Europeanisation and Political Parties in Accession Countries: The Political Parties of Cyprus», ó.п., о. 5.

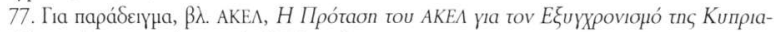

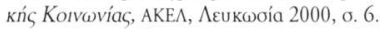

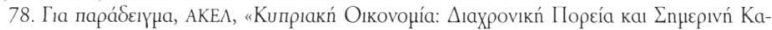

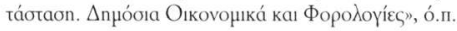




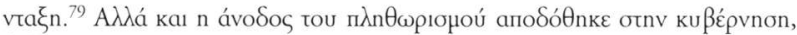

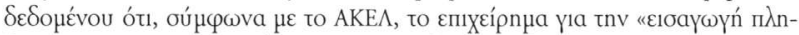

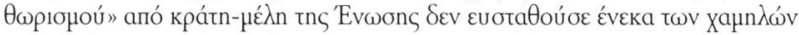

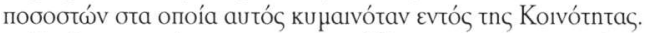

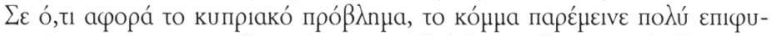

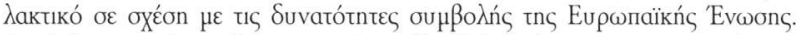

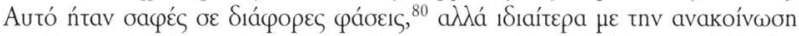

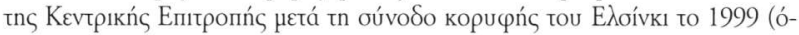

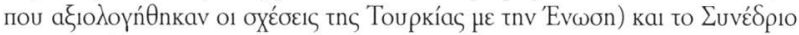
Tou $2000 .{ }^{81}$

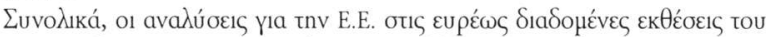

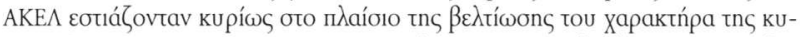

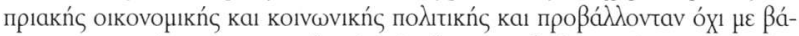

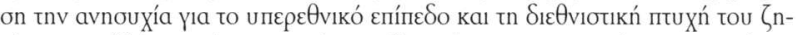

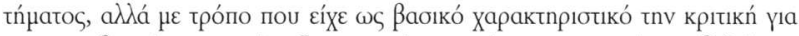

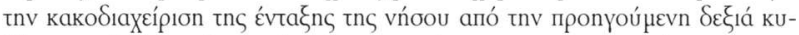

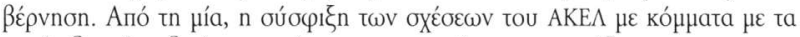

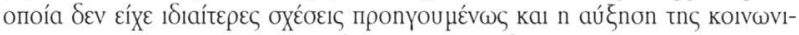

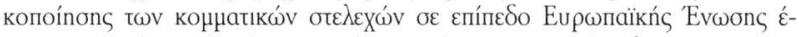

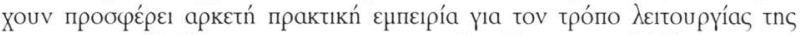

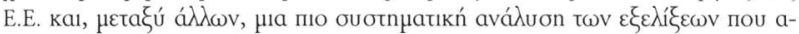

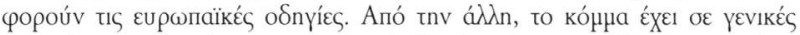

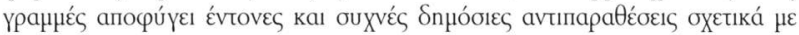

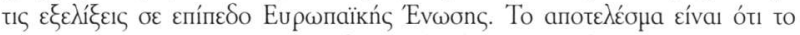

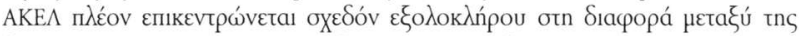

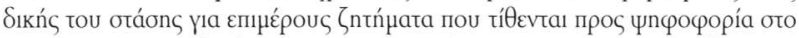

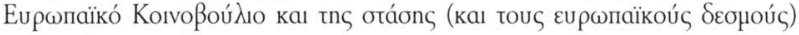

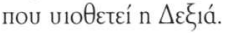

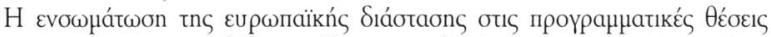

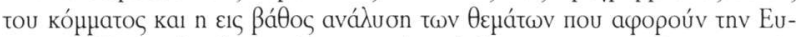

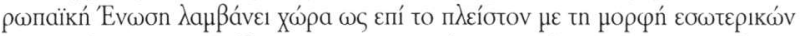

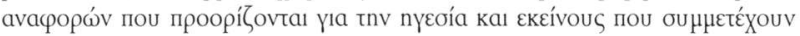

79. Eto ísı, б. 7.

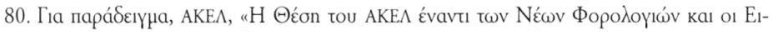

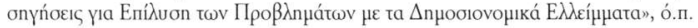

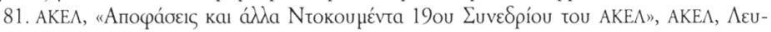
kwớa, 2000, o. 39. 


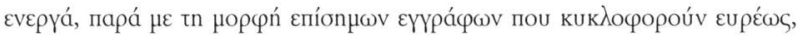

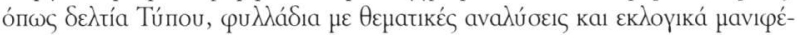

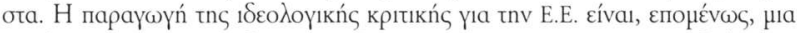

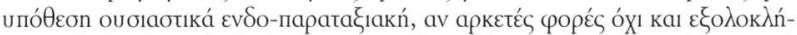

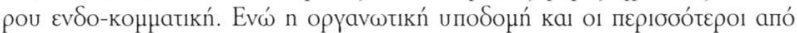

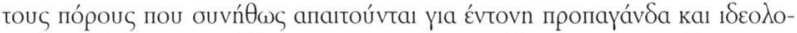

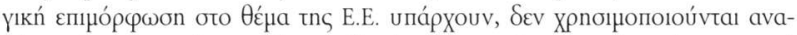

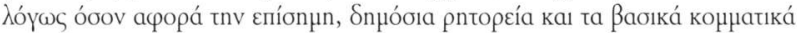

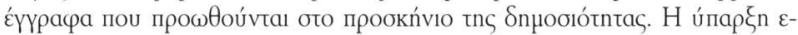

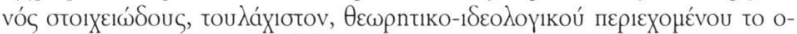

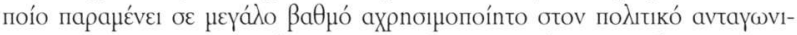

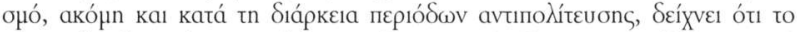

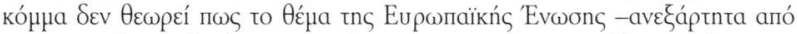

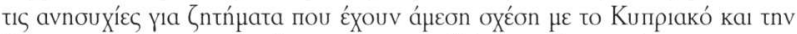

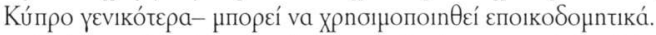

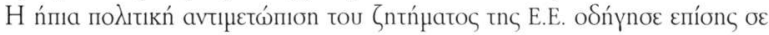

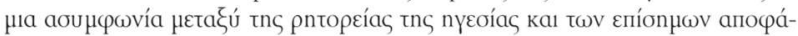

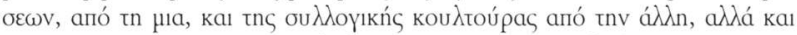

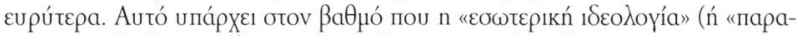

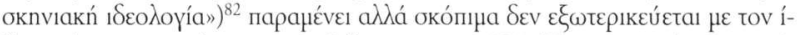

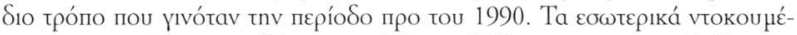

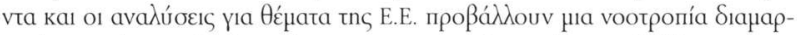

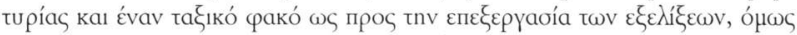

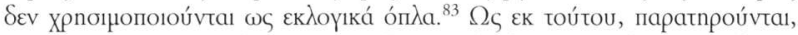

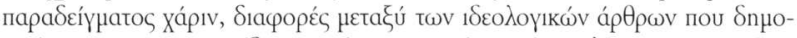

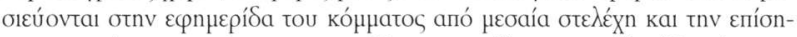

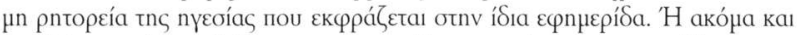

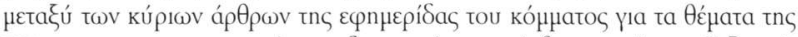

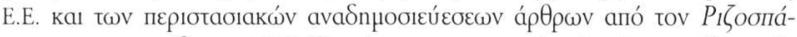

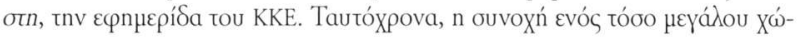

82. B $\lambda$. C. Mudde, The Ideology of the Extreme Right, Manchester University Press, Manchester, 2000, б. 20 кal D. Sainsbury, Swedish Social Democratic Ideology and Electoral Politics, 1944-1948: A Study of the Functions of Party Ideology, Almqvist and Wiksell International, ¿токхо́ $\mu$ in 1980.

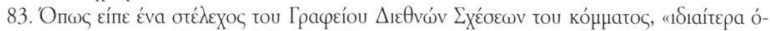

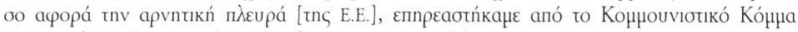

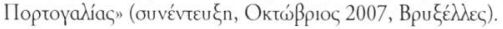




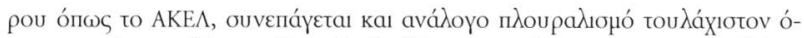

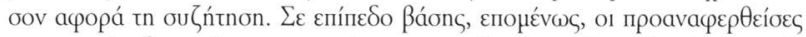

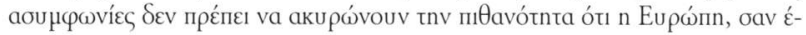

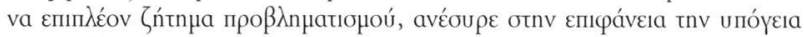

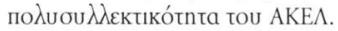

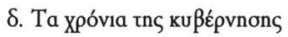

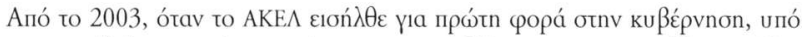

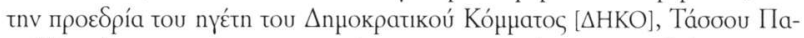

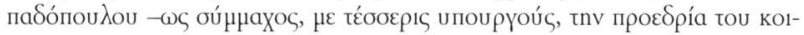

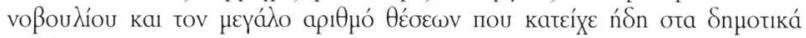

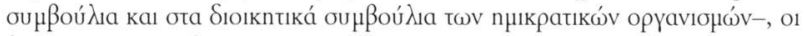

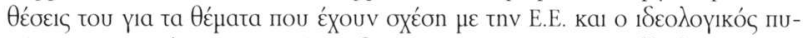

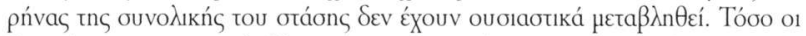

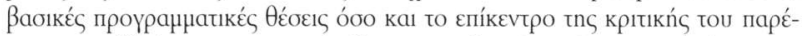

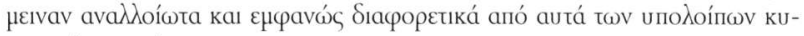

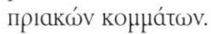

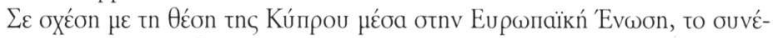

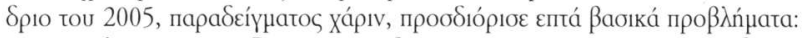

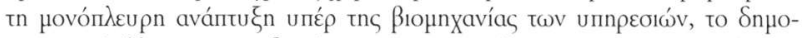

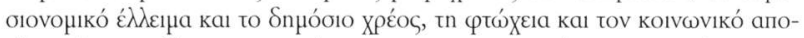

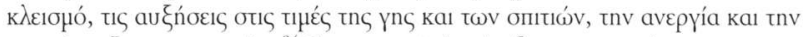

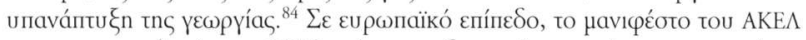

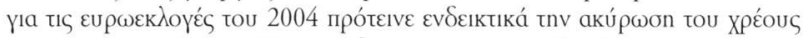

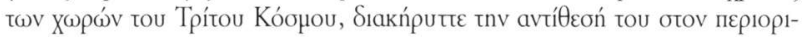

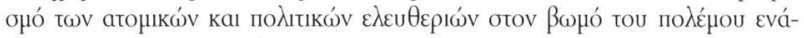

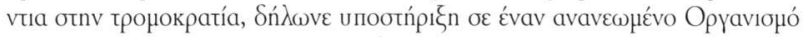

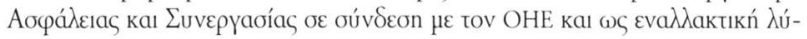

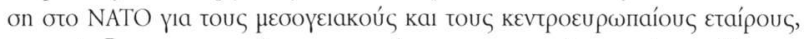

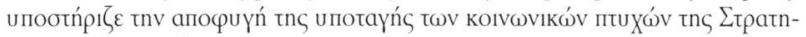

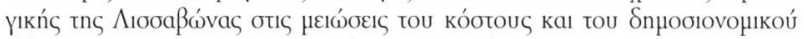

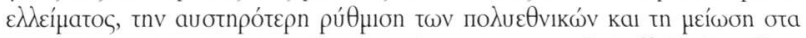

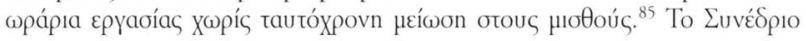

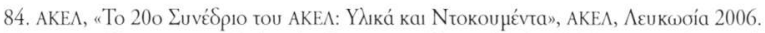

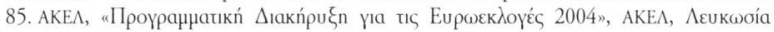
2004 . 


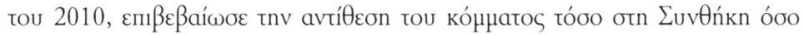

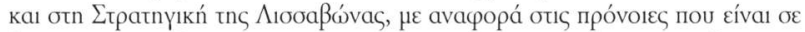

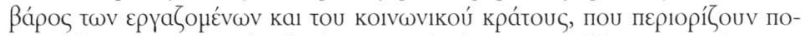

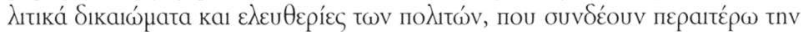

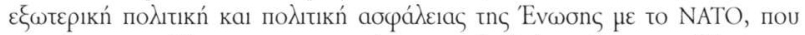

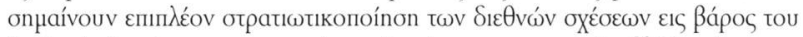

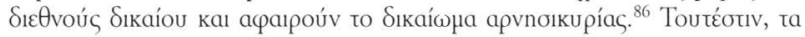

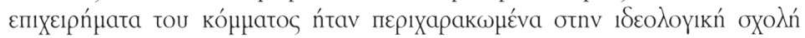

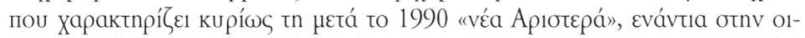

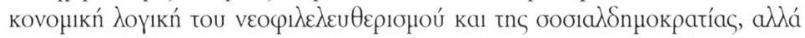

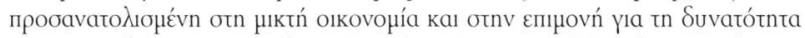

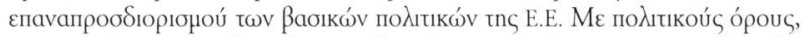

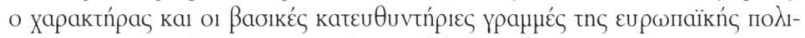

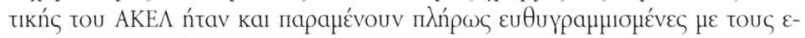

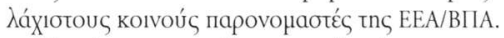

Tautóxpova, парó

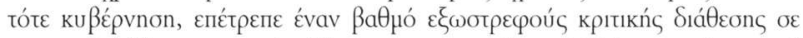

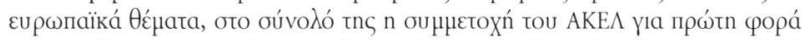

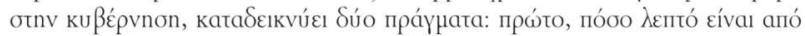

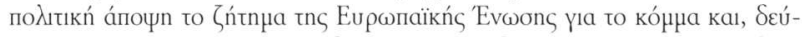

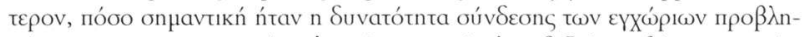

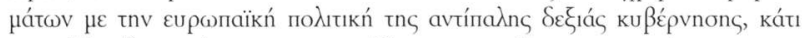

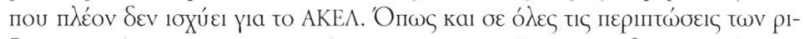

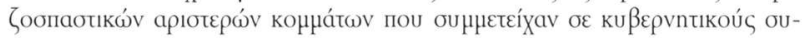

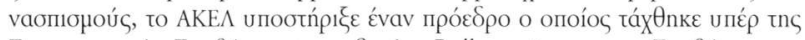

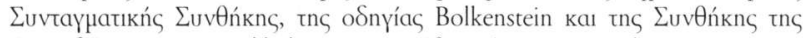

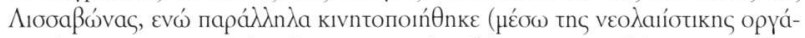

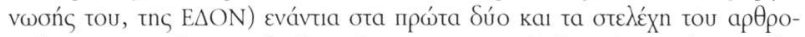

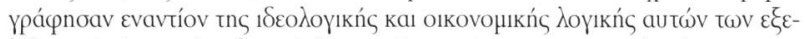

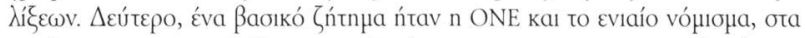

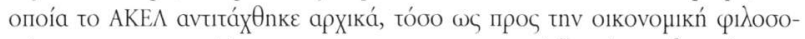

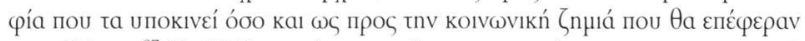

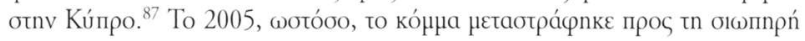

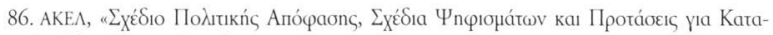

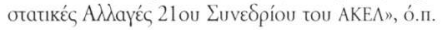

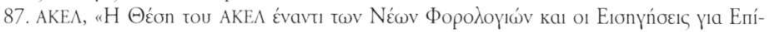

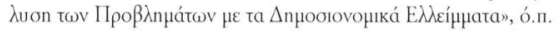




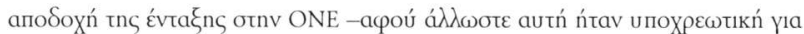

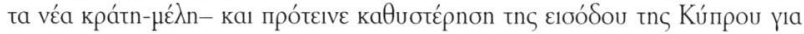

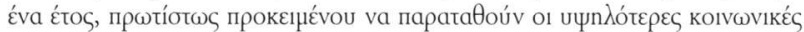

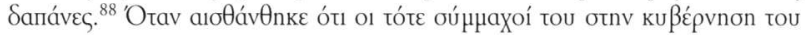

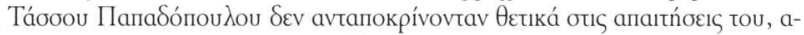

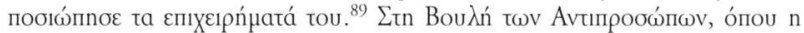

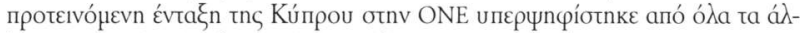

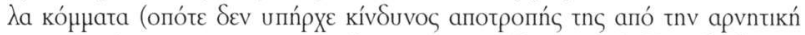
tou чń

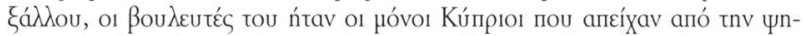

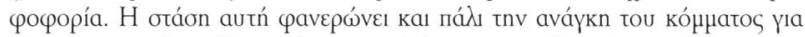

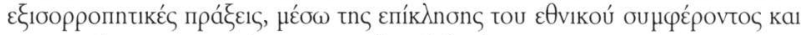

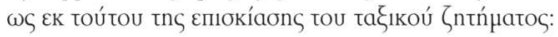

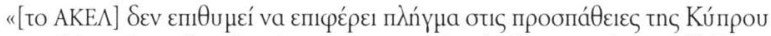

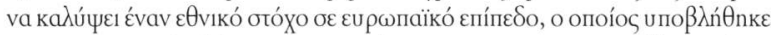

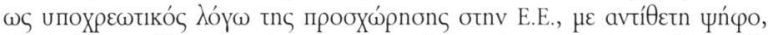

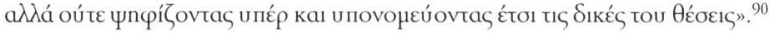

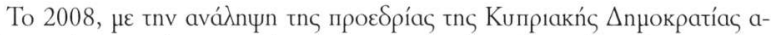

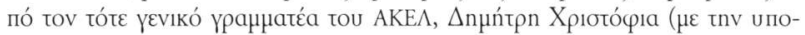

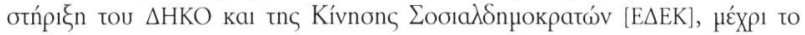

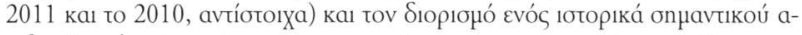

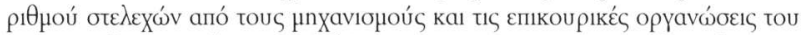

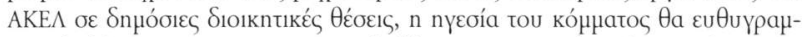

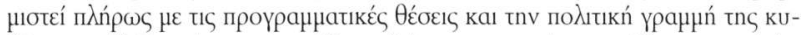

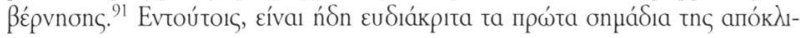

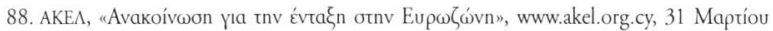
2006.

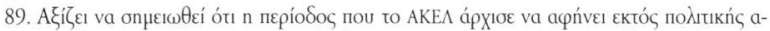

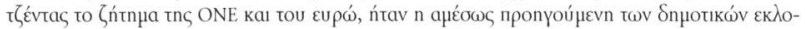

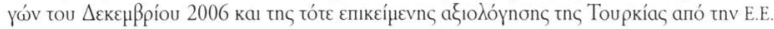

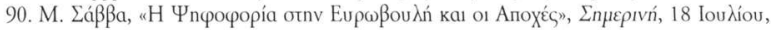
2007, о. 25.

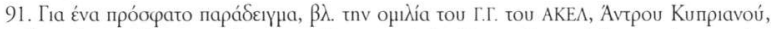

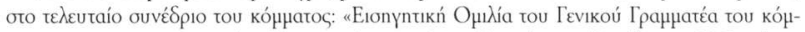

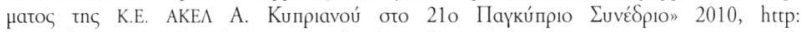
www.edon.org.cy/index.php/arxeio/omilies/eisigitiki-gg-akel. 


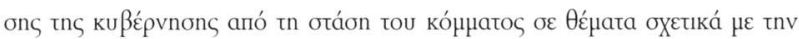
Euр๘паїкń 'Evøon.

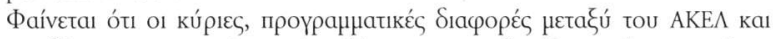

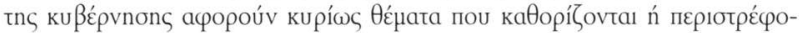

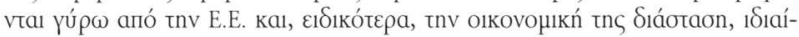

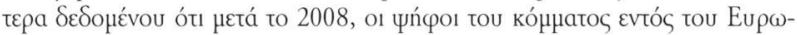

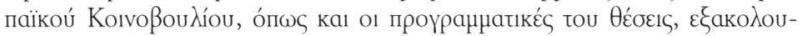

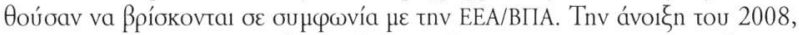

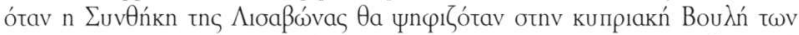

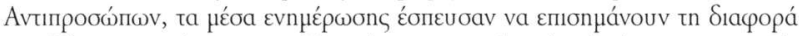

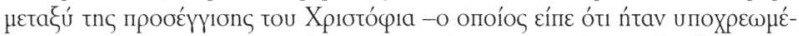

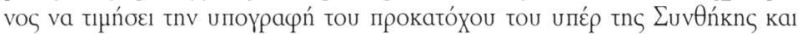

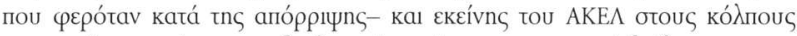

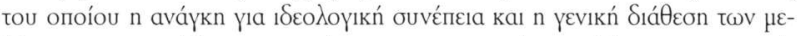

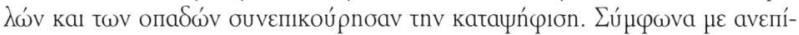

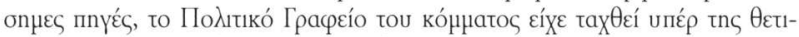

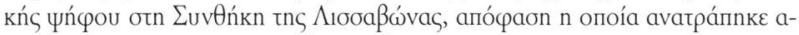

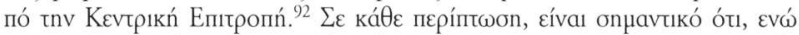

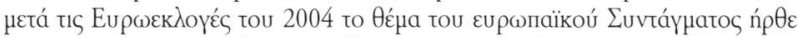

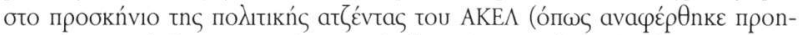

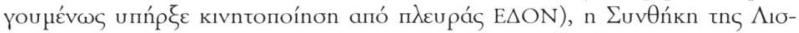

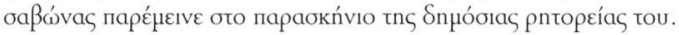

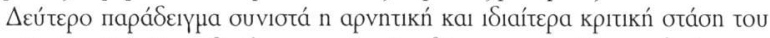

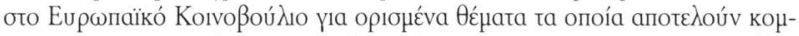

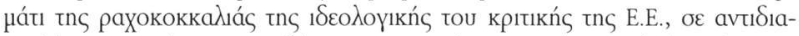

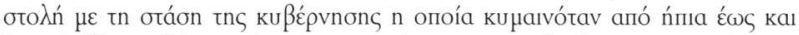

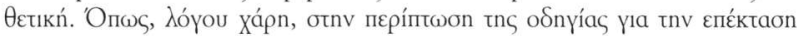

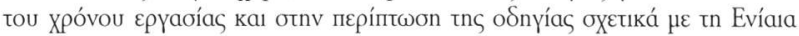

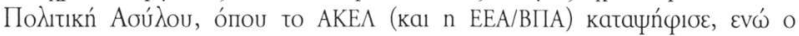

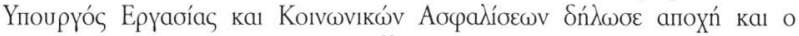

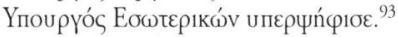

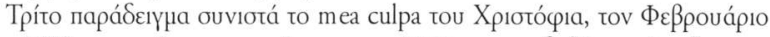

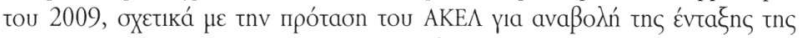

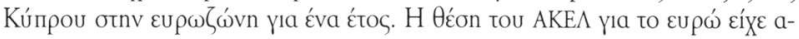

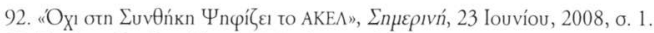

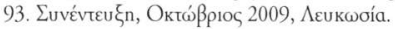




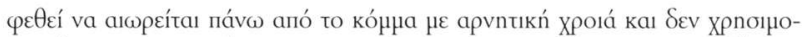

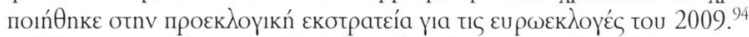

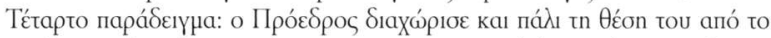

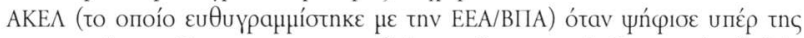

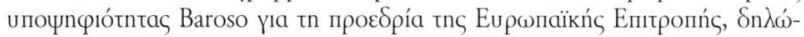

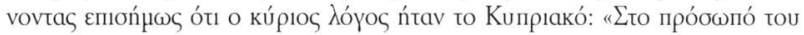

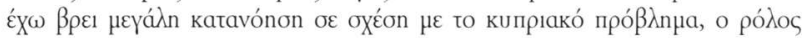

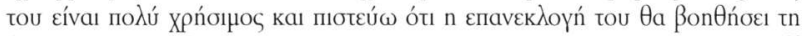

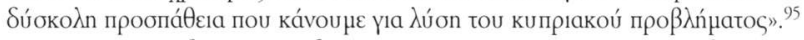

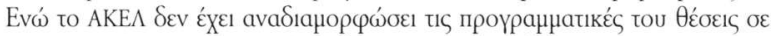

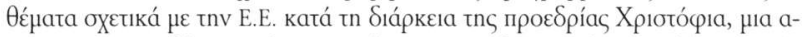

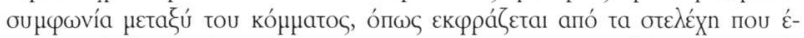

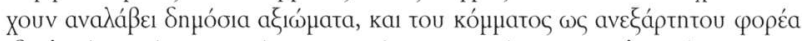

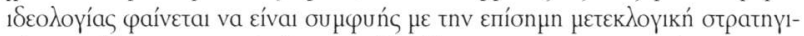

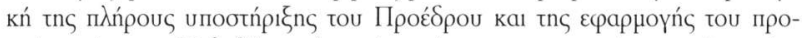

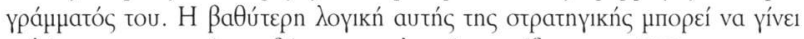

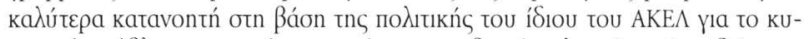

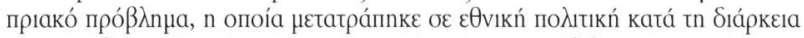

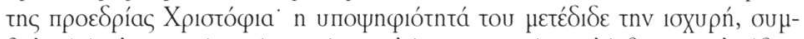

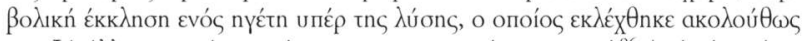

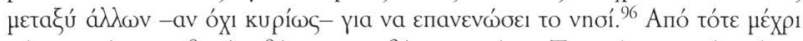

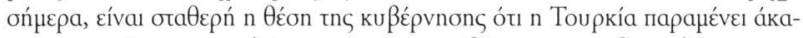

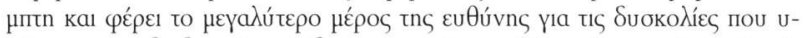

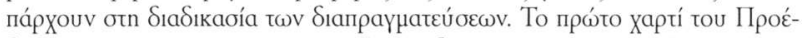

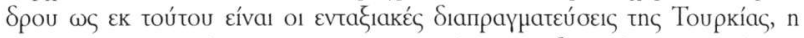

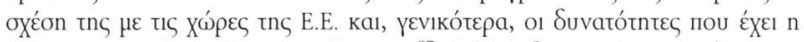

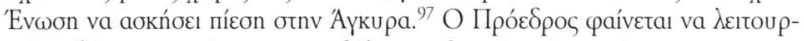

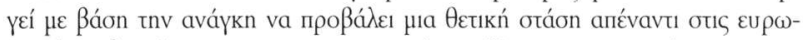

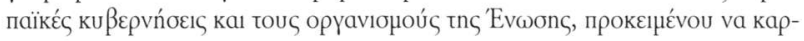

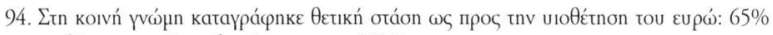

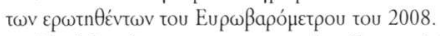

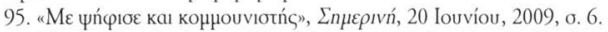

96. B $\mathrm{A}$. G. Charalambous, "The February 2008 Presidential Election in the Republic of Cyprus: The Context, Dynamics and Outcome in Perspectiven, The Cyprus Review, tó $\mu$. 21, тX. 1, 2009, 0. 97-122.

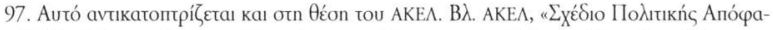

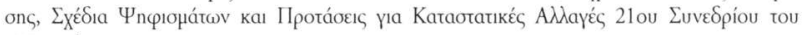
AKEA", ó.п. 


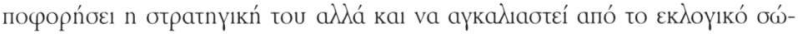

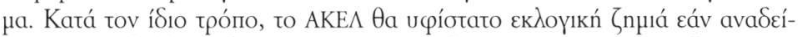

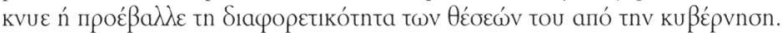

\section{4. ГYMПЕРАЕMATA}

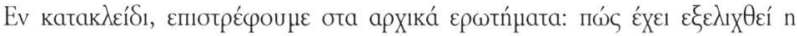

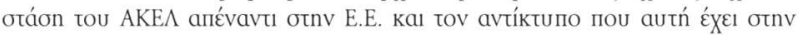

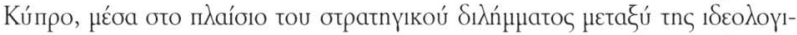

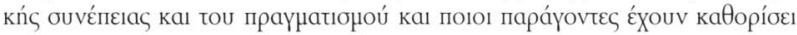

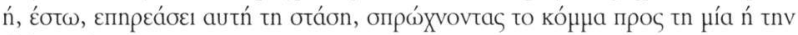

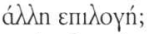

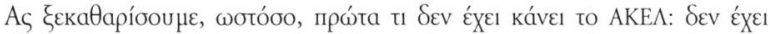

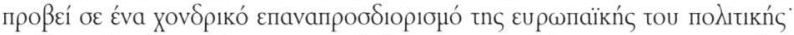

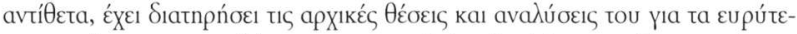

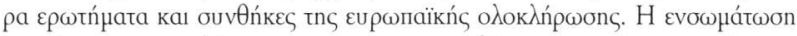

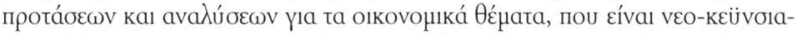

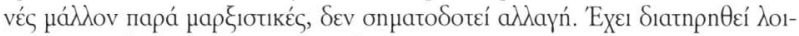

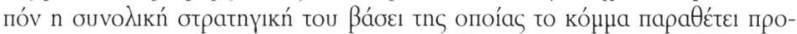

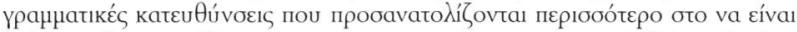

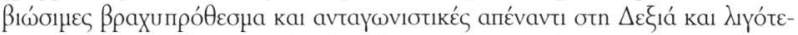

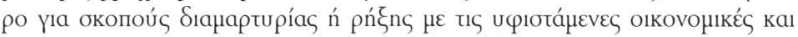

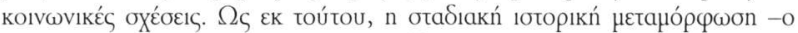

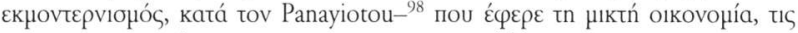

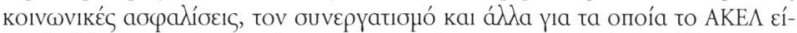

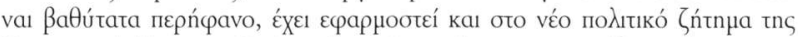

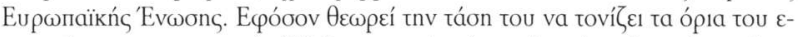

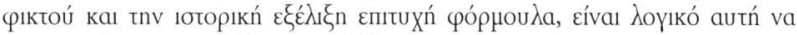

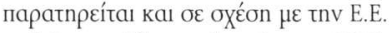

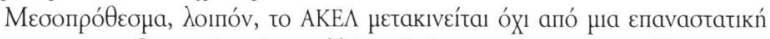

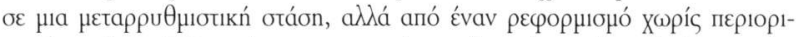

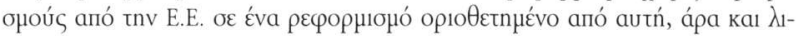

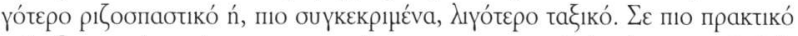

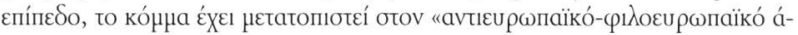

98. A. Panayiotou, "Lenin in the Coffee-shop: the Communist Alternative and forms of non-western modernity", о́.п. 


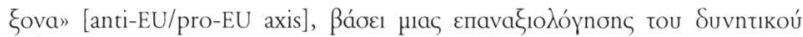

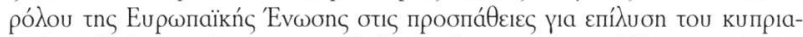

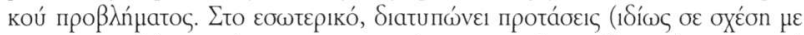

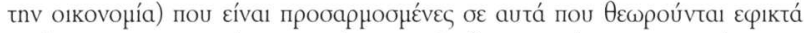

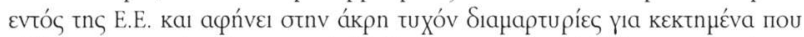

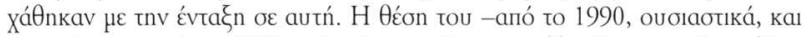

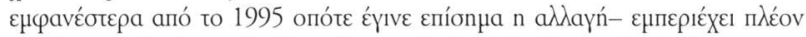

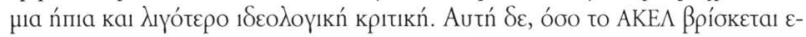

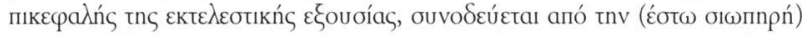

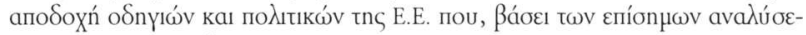

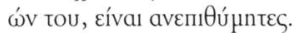

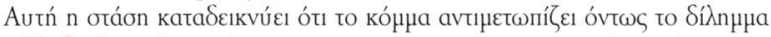

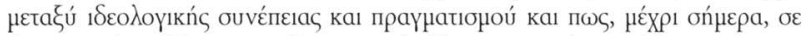

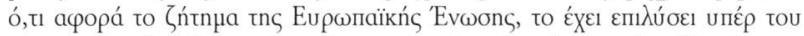

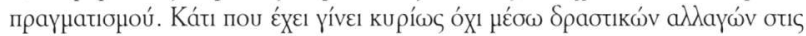

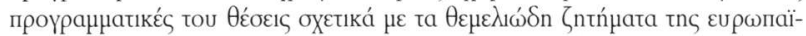

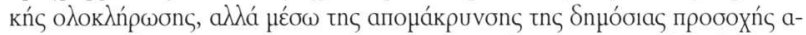

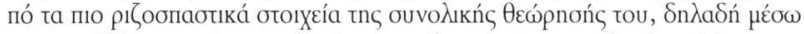

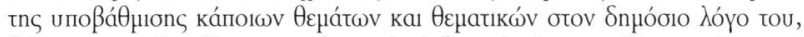

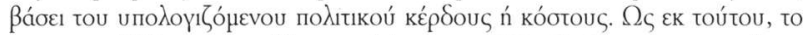

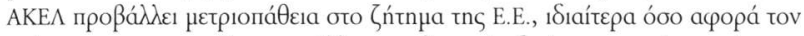

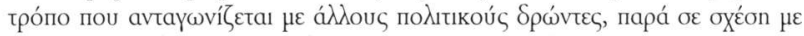

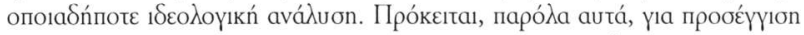

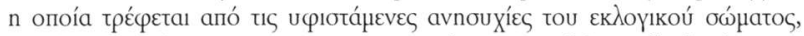

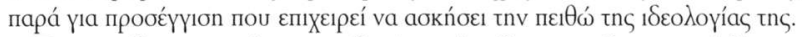

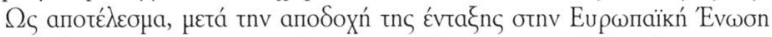

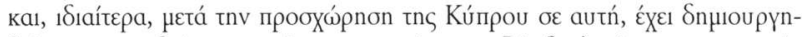

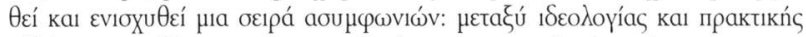

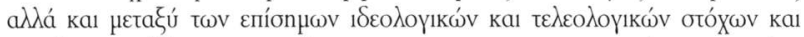

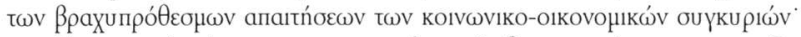

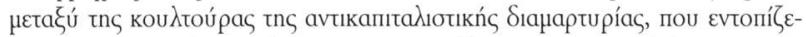

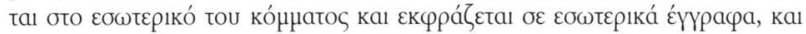

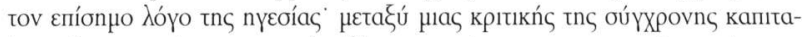

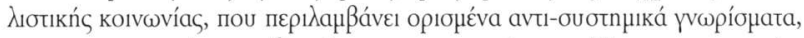

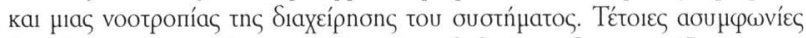

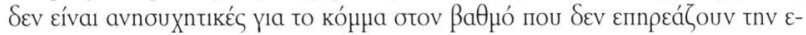

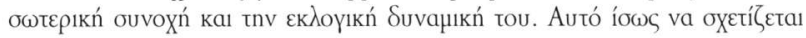




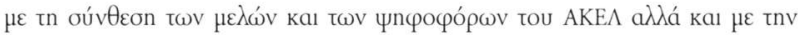

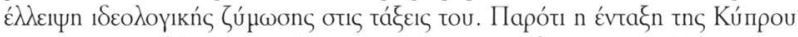

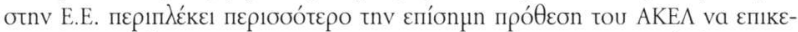

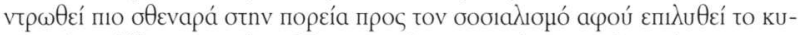

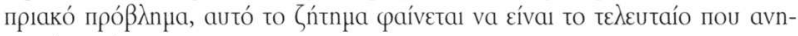

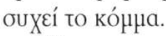

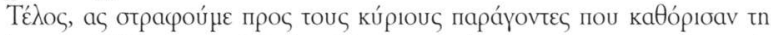

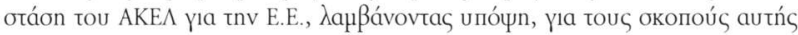

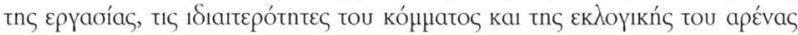

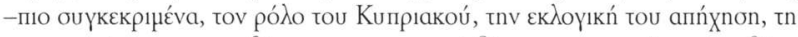

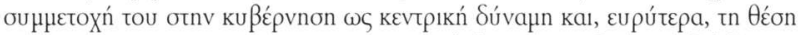

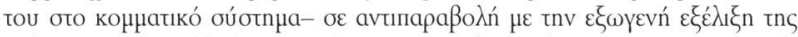

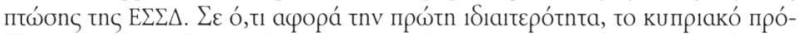

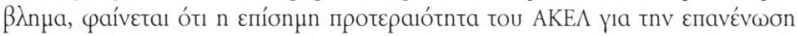

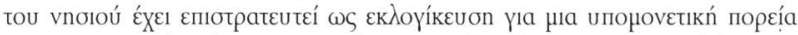

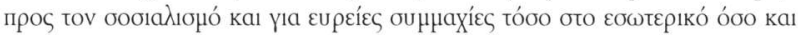

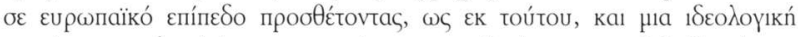

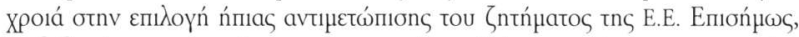

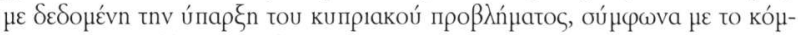

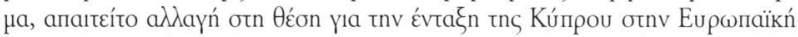

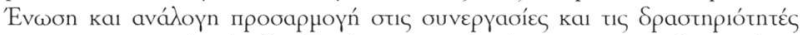

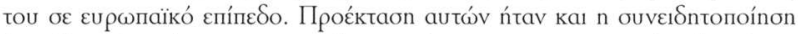

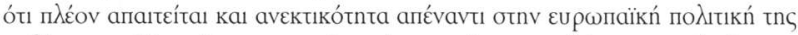

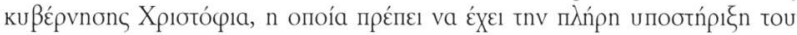

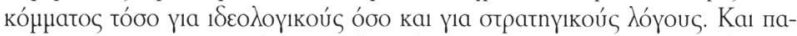

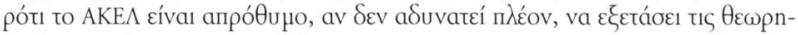

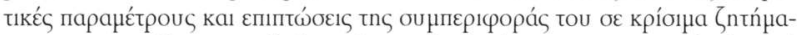

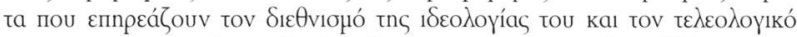

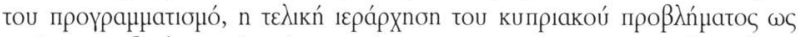

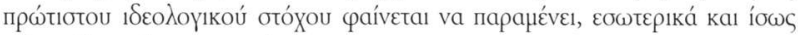

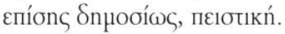

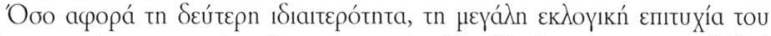

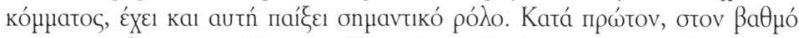

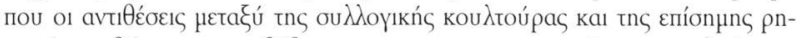

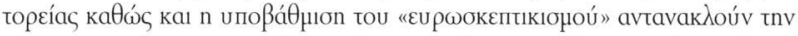

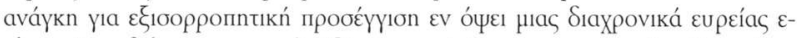

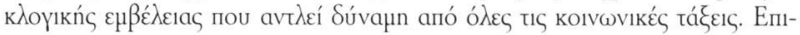




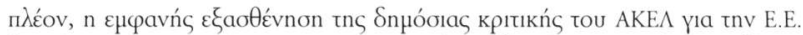

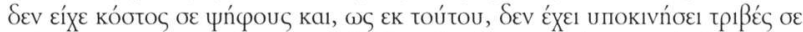

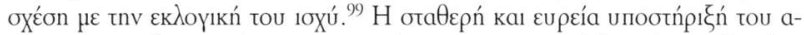

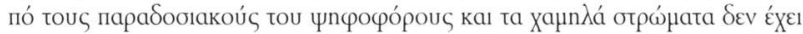

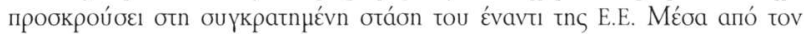

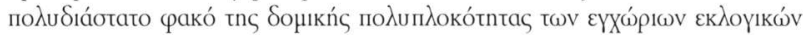

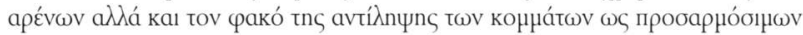

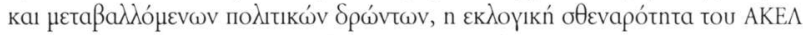

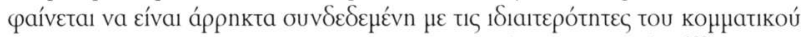

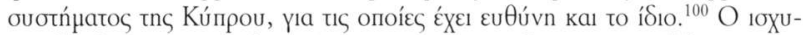

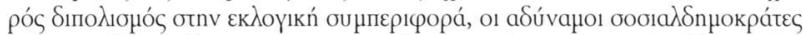

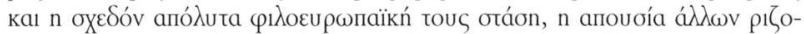

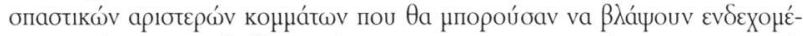

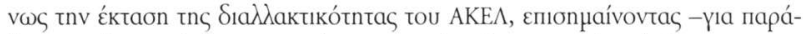

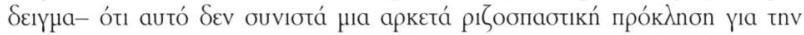

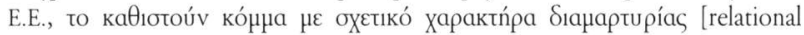

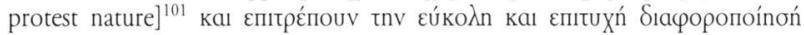
tou aпó ta uпó

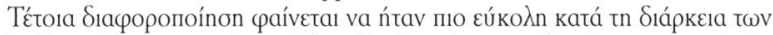

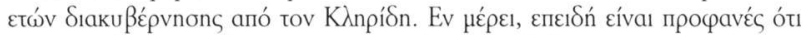

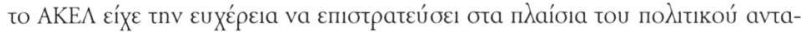

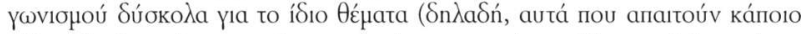

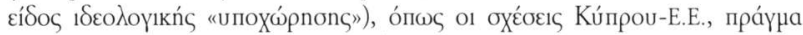

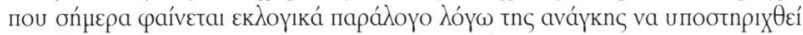

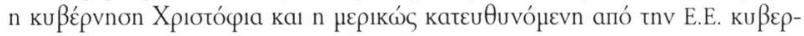

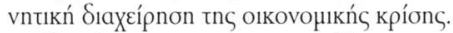

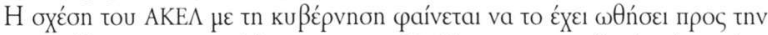

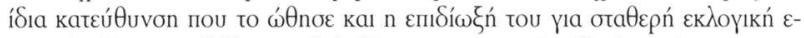

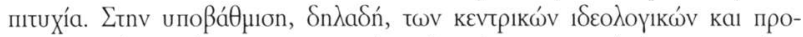

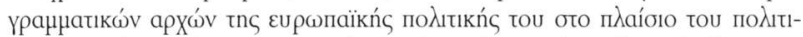

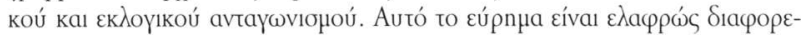

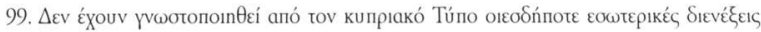

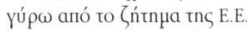

100. G. Charalambous, "The Strongest Communists in Europe: Accounting for AKEL's Electoral Success", ó.r.

101. B $\lambda$. G. Capoccia, "Anti-System Parties: A Conceptual Reassessment", Journal of Theoretical Politics, tón. 14, זx. 1, 2002, б. 9-35. 


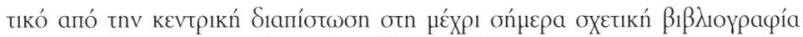

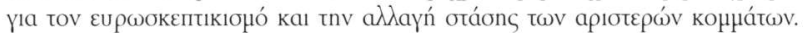

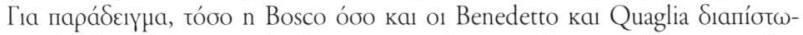

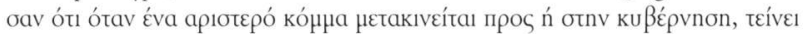

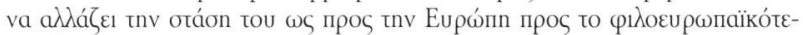

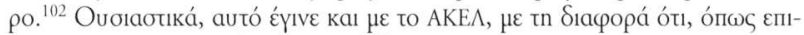

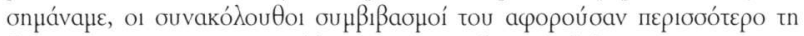

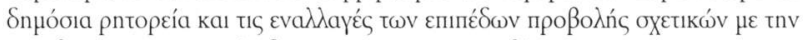

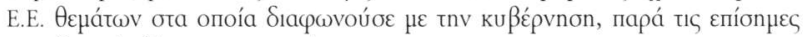

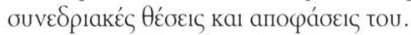

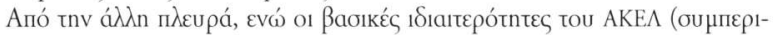

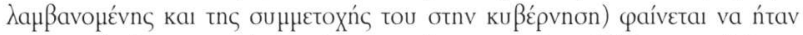

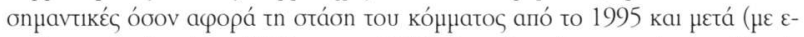

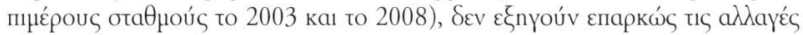

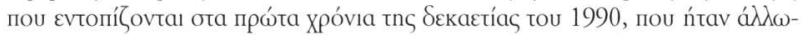

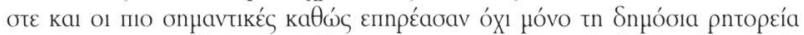

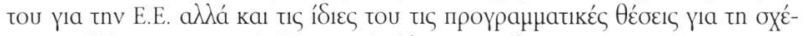

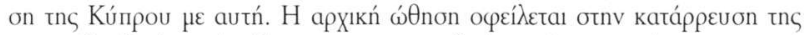

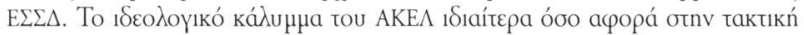

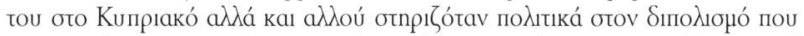

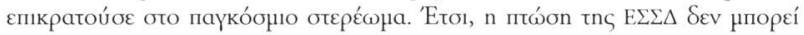

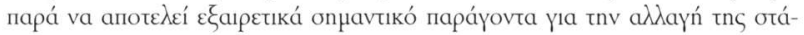

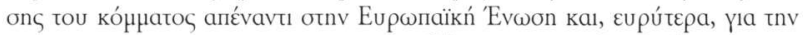

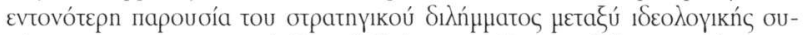

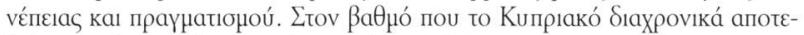

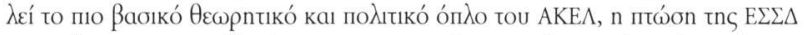

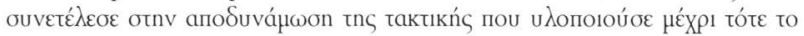

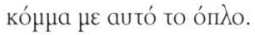

102. A. Bosco, «Four Actors in Search of a Role: The Southern European Communist Par-

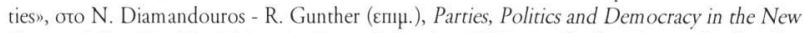
Europe, Johns Hopkins University Press, Baגtúópn 2001, kaı G. Benedetto - L. Quaglia, "The Comparative Politics of Communist Euroscepticism in France, Italy and Spain", ó.n, 